\title{
Transcriptomic Analysis of Ribosome-Bound mRNA in Cortical Neurites In Vivo
}

\author{
-Rebecca Ouwenga, ${ }^{1,2,3}$ Allison M. Lake, ${ }^{2,3}$ David 0’Brien, ${ }^{2,3}$ @Amit Mogha, ${ }^{4} \oplus^{-}$Adish Dani, ${ }^{5,6}$ \\ and $\odot$ Joseph D. Dougherty ${ }^{2,3,6}$ \\ ${ }^{1}$ Division of Biology and Biomedical Sciences, Departments of ${ }^{2}$ Genetics, ${ }^{3}$ Psychiatry, ${ }^{4}$ Developmental Biology, and ${ }^{5}$ Pathology and Immunology, and \\ ${ }^{6}$ Hope Center for Neurological Disorders, Washington University School of Medicine, St. Louis, Missouri 63110
}

Localized translation in neurites helps regulate synaptic strength and development. Dysregulation of local translation is associated with many neurological disorders. However, due to technical limitations, study of this phenomenon has largely been limited to brain regions with laminar organization of dendrites such as the hippocampus or cerebellum. It has not been examined in the cortex, a region of importance for most neurological disorders, where dendrites of each neuronal population are densely intermingled with cell bodies of others. Therefore, we have developed a novel method, SynapTRAP, which combines synaptoneurosomal fractionation with translating ribosome affinity purification to identify ribosome-bound mRNA in processes of genetically defined cell types. We demonstrate SynapTRAP's efficacy and report local translation in the cortex of mice, where we identify a subset of mRNAs that are translated in dendrites by neuronal ribosomes. These mRNAs have disproportionately longer lengths, enrichment for FMRP binding and G-quartets, and their genes are under greater evolutionary constraint in humans. In addition, we show that alternative splicing likely regulates this phenomenon. Overall, SynapTRAP allows for rapid isolation of cell-type-specific localized translation and is applicable to classes of previously inaccessible neuronal and non-neuronal cells in vivo.

Key words: local translation; synaptic translation; synaptoneurosomes; SynapTRAP; TRAP

\section{Significance Statement}

Instructions for making proteins are found in the genome, housed within the nucleus of each cell. These are then copied as RNA and exported to manufacture new proteins. However, in the brain, memory is thought to be encoded by strengthening individual connections (synapses) between neurons far from the nucleus. Thus, to efficiently make new proteins specifically where they are needed, neurons can transport RNAs to sites near synapses to locally produce proteins. Importantly, several mutations that cause autism disrupt this process. It has been assumed this process occurs in all brain regions, but has never been measured in the cortex. We applied a newly developed method measure to study, for the first time, local translation in cortical neurons.

\section{Introduction}

As all mRNA must come from a single cellular location (the nucleus) there is extensive post-transcriptional regulation of RNA

Received Sept. 29, 2016; revised June 29, 2017; accepted July 21, 2017.

Author contributions: R.O. and J.D.D. designed research; R.O. performed research; R.O., A.M., and A.D. contributed unpublished reagents/analytic tools; R.O., A.M.L., D.O., and J.D.D. analyzed data; R.O. and J.D.D. wrote the paper.

This work was supported by the CDI (MD-II-2013-269), and NIH (R21DA038458, R21MH099798, R01NS102272), and key technical support was provided by the Genome Technology Resource (enter at Washington University (supported by NIH Grants P30 CA91842 and UL1TR000448); R.O. was supported by T32 GM081739; J.D.D. is a NARSAD investigator. We thank M. Wong for Thy-1 mice, K. Monk, C. Weichselbaum, and members of the Dougherty Laboratory for helpful comments, N. Pisat, N. Kopp, K. Sakers, and S. Pyfrom for training, advice, and assistance.

Conflict of interest: J.D.D. has received royalties related to TRAP in the past. The remaining authors declare no competing financial interests.

Correspondence should be addressed to Dr. Joseph Dougherty, Dougherty Laboratory, Department of Genetics, 660 South Euclid Avenue, Campus Box 8232, St. Louis, M0 63110-1093. E-mail: jdougherty@genetics.wustl.edu.

DOI:10.1523/JNEUROSCI.3044-16.2017

Copyright $\odot 2017$ the authors $\quad 0270-6474 / 17 / 378688-18 \$ 15.00 / 0$ within cells, including localization of mRNA to specific subcellular compartments. Localized translation of mRNA in specific subcellular compartments allows more precise regulation of local protein concentrations, and thus modifies the functional capacity of the compartment. A clear example exists in the nervous system where neurons demonstrate remarkable capacity for regulated local translation with individual mRNAs accumulating near activated synapses (Steward et al., 2014). Local translation in these dendrites supports synaptic strengthening (Kang and Schuman, 1996). Although ultrastructural evidence for localized translation in dendrites was first provided $>30$ years ago (Steward and Levy, 1982), it is still not clear which mRNAs are translated in cortical neurites nor how this translational profile changes across cell types.

In addition, several psychiatric diseases have been observed to have perturbations in neuronal local translation. For example, Fragile X syndrome, an Autism Spectrum Disorder (ASD)-related 
syndrome, and other ASD-associated disorders, are caused by mutations in known local translational regulators (Kelleher and Bear, 2008; Ronesi and Huber, 2008). Interestingly, it has been shown that the degree of translational perturbation in models of Fragile $\mathrm{X}$ can vary across brain regions (Qin et al., 2005); however, it is unclear the extent to which local translation also differs across cell types in response to disease, development, or activity. To study these kinds of perturbations, a method is needed to enrich for both processes-localized and cell-type-specific mRNA.

Previously, studies have used cell-culture based methods for examining the RNAs found in neurites in vitro (Poon et al., 2006; Taliaferro et al., 2016) in addition to physical methods (LCM and manual dissection) to isolate processes of certain populations in vivo. In vivo, these isolation techniques were limited to cell types with neurites that grow in a physical layer distant from the cell body, including the CA1 synaptic neuropil of the hippocampus (Poon et al., 2006; Zhong et al., 2006; Cajigas et al., 2012; Ainsley et al., 2014), and the Purkinje cell layer of the cerebellum (Kratz et al., 2014). Likewise, a recent study was able to capture translating mRNAs from retinal-geniculate axons because only retinal cells expressed the necessary tag (Shigeoka et al., 2016). Although valuable for assessing local translation in these limited neuronal cell types, this approach is unable to assess localization in the intermingled dendrites of neurons found in most regions of the brain, and provides no evidence as to whether the mRNAs are on ribosomes, a prerequisite for local translation. The development of a method to isolate the ribosome bound mRNAs from neurites of densely intermingled cells would allow analysis of local translation across a larger number of cell types in the CNS.

Here, we describe SynapTRAP, a novel method that permits the harvesting of ribosomes from the intermingled processes of specific cell types in vivo. This method combines subcellular fractionation on a sucrose-Percoll gradient with translating ribosome affinity purification (TRAP) to identify ribosome bound mRNA from neurons in the synaptoneurosomal fraction (SNF). Because of the ability to harvest neuronal processes from a variety of neuronal types, cell fractionation is effective for isolating neuronal projections of cell types that are intermingled with other cells' bodies, but fractionation alone provides no cell-type specificity. The TRAP technique uses a neuronal cell-type-specific promoter to express an eGFP tagged ribosome in only the cell type of interest (Doyle et al., 2008). Combining subcellular fractionation and TRAP, SynapTRAP allows for the identification of ribosome bound mRNA from neural projections of transgene-expressing cells. This builds upon prior work combining TRAP with laminar or regional dissections (Ainsley et al., 2014; Kratz et al., 2014; Shigeoka et al., 2016), now extending the methodology to allow for analysis of a myriad of CNS cell types where dendrites are not in clearly dissectible lamina.

Next, we demonstrate the utility of SynapTRAP by harvesting, for the first time, the RNA from the intermingled processes of cortical neurons in vivo. We validate these findings with independent methods: SynapTRAP results are consistent with in situ RNA localization, and bioinformatics approaches can identify motifs and other features of the candidate local translation transcripts that are consistent with previous findings. Finally, we show that splicing does appear to regulate several mRNAs' localization to neuronal processes; however, there is no overall significant enrichment for differential splicing in the localization of RNAs within the cell. Overall, SynapTRAP allows for the high throughput investigation of localized translation in cell types never previously accessible in vivo.

\section{Materials and Methods}

Animals. All procedures were performed in accordance with the guidelines of Washington University's Institutional Animal Care and Use Committee. Mice were maintained in standard housing conditions with food and water provided ad libitum. The $\mathrm{Tg}$ (Snap25-eGFP/Rpl10a) $)^{\mathrm{ID} 362 \mathrm{Jd} d}$ (RRID: IMSR_JAX:030273; Dougherty et al., 2012) bacTRAP mouse was used for SynapTRAP experiments and the Tg(Thy1-EGFP)M ${ }^{\text {Irs/J }}$ (RRID: IMSR_JAX:007788) line was used for FISH analysis.

Sucrose Percoll gradient preparation of a SNF. The sucrose-Percoll gradient was modified from (Westmark et al., 2011). Briefly, each column was loaded with $2 \mathrm{ml}$ of homogenated sample in a modified homogenization buffer ( 5 mм Tris-Cl, pH 7.5, 250 mм sucrose, 0.5 mм DTT, $100 \mu \mathrm{g} / \mathrm{ml}$ cycloheximide, $1 \mathrm{~mm}$ tetrodotoxin (Tocris Bioscience, 1069), 35 U rRNAsin (Promega, N2511), 35 U SUPERaseIn (Ambion, AM2694) and 1 tablet/10 ml cOmplete mini EDTA-free protease inhibitor cocktail tablets (Roche, 4693159001)). Gradients were made as described previously (Westmark et al., 2011) in open-top tubes (Seton, 5042) and spun at $32,500 \times g$ for $5 \mathrm{~min}$ in a Sorvall RC-5C without brake. To harvest the SNF a $16 \mathrm{~g}$ needle was used to puncture the bottom of the tube for collection of sequential fractions. The initial $1 \mathrm{ml}$ consists of large organelles and was discarded. The next $3.5 \mathrm{ml}$ was collected as the SN-containing fractions. A salt lysis buffer (100 mM HEPES, $1.5 \mathrm{M} \mathrm{KCL}$, $10 \% \mathrm{NP}-40,50 \mathrm{~mm} \mathrm{MgCl}_{2}$, and $30 \mathrm{~mm}$ DHPC) was added to the SNF at $10 \%$ volume to lyse the $\mathrm{SN}$ membranes and stabilize the exposed ribosomes.

SynapTRAP and library preparation. For each of three replicates, the cortices of three $\operatorname{Tg}(\text { Snap25-eGFP/Rpl10a })^{\text {JD362Jdd }}$ bacTRAP mice at $21 \mathrm{~d}$ post-birth were pooled (not separated by sex), and homogenized in $3.5 \mathrm{ml}$ modified homogenization buffer (described above) in glass homogenizer (10 strokes each pestle, Kontes $7 \mathrm{ml}$ ), and spun at $1000 \times \mathrm{g}$ in a Sorval RT7 for $10 \mathrm{~min}$ at $4^{\circ} \mathrm{C}$. The supernatant was split into two samples. For the whole-cell homogenate (WCH) samples, $500 \mu$ lof the supernatant was incubated with $50 \mu \mathrm{l}$ of Salt lysis buffer (described above) for $15 \mathrm{~min}$ and spun at $20,000 \times \mathrm{g}$ for $15 \mathrm{~min}$ at $4^{\circ} \mathrm{C}$ to reduce cell debris. The remaining supernatant $(2 \mathrm{ml})$, for the $\mathrm{SN}$ samples, was fractionated on a discontinuous sucrose-Percoll gradient to harvest the SN rich sample as described above. Then, a portion of the WCH and SNF samples underwent TRAP for affinity purification of neuronal ribosomes, as described previously (Heiman et al., 2008). Briefly, samples were incubated with anti-eGFP-coated biotinylated magnetic beads [30 $\mu \mathrm{l}$ beads and $50 \mu \mathrm{g}$ each of two anti-GFP antibodies (clone 19f7, 19fc 8 ) per sample]. After a $4 \mathrm{~h}$ incubation at $4^{\circ} \mathrm{C}$, samples were washed using a high salt wash and resuspended. RNA from the parallel affinity purified samples (Whole-cell TRAP and SynapTRAP) and matched background controls (WCH and SNF) was harvested using a Qiagen RNEasy MinElute kit. RNA concentration was measured using a Nanodrop and diluted to $<5 \mathrm{ng} / \mu \mathrm{l}$ before being assessed for quality and concentration using an Agilent RNA 6000 Pico Kit on an Agilent Bioanalyzer. RNA samples were reverse transcribed into cDNA and amplified using Nugen Ovation RNA-seq System V2 kit (Nugen, 7102), per the manufacturer's instructions. cDNA was fragmented using a Covaris E210 sonicator using duty cycle 10 , intensity 5 , cycles/burst 200 , time $180 \mathrm{~s}$. cDNA was blunt ended, had an A base added to the $3^{\prime}$ ends, and then had Illumina sequencing adapters ligated to the ends. Ligated fragments were then amplified for 12 cycles using primers incorporating unique index tags. Libraries were normalized and sequenced on an Illumina HiSeq2500 using single reads extending 50 bases by the Genome Technology Access Center at Washington University.

Sequencing, analysis, and data availability. Analysis is as previously described (Reddy et al., 2017). Reads were trimmed of adapter sequences with Trimmomatic (Bolger et al., 2014; v0.32, RRID: SCR_011848), ribosomal RNAs were removed by mapping to rRNA sequences using Bowtie2 (Langmead and Salzberg, 2012; RRID: SCR_005476), and remaining reads were aligned to Ensembl v75 of the mouse genome using STAR (Dobin et al., 2013). Counts were performed by HTseq (Anders et al., 2015; RRID: SCR_005514). Because of varying levels of mitochondrial rRNA between sample types, tRNA, mitochondrial, and remaining eukaryotic rRNA reads were excluded, as were genes without at least two 
counts per million (CPM) in two samples. Counts were then normalized to final CPM based on the final library sizes. Differential expression was identified using edgeR (McCarthy et al., 2012; RRID: SCR_012802). All data are available at GEO: GSE74506.

For downstream analysis, two gene lists were defined. The first consists of candidates for local translation in neuronal processes (local translation candidates). These 153 genes had transcripts enriched both in the discontinuous Percoll gradient (higher expression in the SNF than in the WCH, $p<0.05$ ) and through TRAP (higher expression in the SynapTRAP sample than in the fraction, $p<0.05$; Eq. 1 ).

Local translation candidates

$$
=\left(\mathrm{CPM}_{\text {SynapTRAP }}>\mathrm{CPM}_{\mathrm{SNF}}\right) \cap\left(\mathrm{CPM}_{\mathrm{SNF}}>\mathrm{CPM}_{\mathrm{WCH}}\right)
$$

The second list consists of candidates for transcripts that are neuronal, but not transported to cellular processes (somatic translation candidates). These 315 genes had transcripts that were depleted by the discontinuous Percoll gradient (lower expression in the SNF than in the WCH, $p<0.05$ ) but still enriched by TRAP (higher expression in the TRAP sample than in the WCH, $p<0.05$; Eq. 2).

Somatic translation candidates

$$
=\left(\mathrm{CPM}_{\mathrm{WCH}}>\mathrm{CPM}_{\mathrm{SNF}}\right) \cap\left(\mathrm{CPM}_{\mathrm{TRAP}}>\mathrm{CPM}_{\mathrm{WCH}}\right)
$$

Fluorescent in situ hybridization (FISH). In situ hybridizations were performed on $20 \mu \mathrm{M}$ coronal brain slices from three male 5-week-old $\mathrm{Tg}$ (Thyl-EGFP) $\mathrm{M}^{\mathrm{Jr} / \mathrm{J}}$ mice following $4 \%$ paraformaldehyde transcardial perfusion, $12 \mathrm{~h}$ incubation in $15 \%$ sucrose in PBS, and $12 \mathrm{~h}$ in $30 \%$ sucrose in $\mathrm{PBS}$ at $4^{\circ} \mathrm{C}$. Sections on slides were postfixed in $4 \%$ paraformaldehyde and acetylated (800 $\mu$ l triethanolamine, $110 \mu \mathrm{l} 10 \mathrm{~N} \mathrm{NaOH}$, $45 \mathrm{ml} \mathrm{H}_{2} \mathrm{O}, 125 \mu \mathrm{l}$ acetic anhydride). Slides were hybridized at $63^{\circ} \mathrm{C}$ with a 100 ng Dig-labeled antisense RNA probe created with T7 polymerase (Promega, P2075), from PCR products using primer sequences from Allen Brain Atlas (Lein et al., 2007), and DIG RNA Labeling Mix (Roche, 11277073910) according to the manufacturer's protocol. Probe detection was performed using Sheep Anti-Dig-POD (Roche, 11207733910) followed by Tyramide Signal Amplification Cyanine 3 Tyramide (PerkinElmer, NEL704A001KT). Samples were imaged on a PerkinElmer UltraView Vox spinning-disk confocal microscope. For each probe, nine total slices from three 5-week-old mice were imaged for GFP-positive neurites using a $63 \times$ oil lens. Images were quantified using ImageJ software using macros that were consistent across probes. GFP images were converted to a black and white image using a threshold on brightness and then measured for the percentage area of GFP. Any soma in the images were removed from analysis by masking. Probe images were then also converted to a black and white image using a threshold on brightness. Each probe and corresponding masked GFP image were overlaid and all the probe puncta not overlapping with the GFP image were thus masked. The remaining overlapping probe puncta were quantified. The number of puncta was divided by the area of the GFP signal for final analysis. Significance of overlap was determined with two-tailed $t$ test between each probe and the no-probe control.

Camk2a (amplified from pcTOPOII plasmid, cut with SpeI; Dani et al., 2010)

F-AGT CTC CAA GCC AAC CCC

R-CCT GGT GTG CGC TCT AT

Snph

F-AGA GTC TCT GAG TGT GCT TCC C

R-TAA TAC GAC TCA CTA TAG GGA GTT GGA CTA AAT GCC AGT GGT

Nsmf

F-GAC TGG GAC ACA GAG AAA GGT C

R-TAA TAC GAC TCA CTA TAG GGA TTG TTA ATC TGG ACC ACC AGG

Mllt6

F-GTT GTC TCA ACA GCC TGA CAG A

R-TAA TAC GAC TCA CTA TAG GGC TCC AGT CTC TCT CCT CCA TGT
Hist $3 h b a$

F-AGC CAG TGC AGC AGG ATG

R-TAA TAC GAC TCA CTA TAG GGA AGA GCC TTT GGG TTG GG

Quantitative PCR. To confirm replication of RNA enrichment by the SynapTRAP three additional independent biological replicates of the WCH, SNF, and SynapTRAP were collected as described above and reverse transcribed using Quanta qScript Reverse Transcriptase (Quanta, 84002). Three technical replicates of each of these samples were quantified with iTaq Universal Sybr green (Bio-Rad, 1725120) on a QuantStudio 6 Flex (Applied Biosystems) in a $10 \mu \mathrm{l}$ volume with amplicons $<200 \mathrm{nt}$. $\beta$-Actin was used as an endogenous control. Statistical testing was determined by ANOVA with five degrees of freedom in R statistical software. Primer sequences from PrimerBank (Wang et al., 2012) were as follows:

Lcp1 PBID: 31543113a1

F-TCC GTG TCT GAC GAA GAA ATG

R-GCG GCC TTG AAC AAG TCA T

Gsn PBID: 28916693al

F-ATG GCT CCG TAC CGC TCT T

R-GCC TCA GAC ACC CGA CTT T

Neurl1a PBID: 15420883a1

F-ACT ATC CAC GAC TCC ATC GGG

R-AGG ATC TGG GAG CCC TTA GTG

Nsmf PBID: 26334509a1

F-GAG GCC ATG TCC TCG GTA G

R-GCG GTT CTC AGG GTG ACT C

Myh14 PBID: 29336026a1

F-CAG TGA CCA TGT CCG TGT CTG

R-CGT AGA GGA ACG ATT GGG CTG

Armc6 PBID: 12846520a1

F-CCC AGG AAA CCT TTG ATG CTG

R-GCC ATC CAG TGA TAC TTT CGG TA

Cpne6 PBID: 6753510a1

F-CAA AGC CGC ATC CAT GTG TG

R-TTG AAC AGG AGC GAA GCA CC

Tesc PBID: 118130497c1

F-GCT GCA TCG GAG GTT CAA G

R-GAT TTT GGA TCG GAT CGG GTT

Camk2a PBID: 161086916c1

F-TGG AGA CTT TGA GTC CTA CAC G

R-CCG GGA CCA CAG GTT TTC A

Snap25 PBID: 6755588a1

F-CAA CTG GAA CGC ATT GAG GAA

R-GGC CAC TAC TCC ATC CTG ATT AT

Shank3 PBID: 255918226c1

F-CCG GAC CTG CAA CAA ACG A

R-GCG CGT CTT GAA GGC TAT GAT

Sox10 PBID: 226423936c2

F-AGG TTG CTG AAC GAA AGT GAC

R-CCG AGG TTG GTA CTT GTA GTC C

Electron microscopy of the SNF. An SNF preparation was performed as described above and pelleted to concentrate the sample via $15 \mathrm{~min}$ at $15,000 \times g(11,000 \mathrm{rpm}$ in an SS-34 rotor $)$ at $4^{\circ} \mathrm{C}$. Pellets were fixed in $4 \%$ paraformaldehyde in $0.1 \mathrm{M}$ sodium phosphate buffer for $30 \mathrm{~min}$. After washing with phosphate buffer, pellets were placed on filter paper soaked with $0.1 \mathrm{M}$ sodium phosphate buffer and cut into four to six pieces with a razor blade. Each piece of filter paper was processed with $0.1 \%$ osmium tetraoxide in $0.1 \mathrm{~m}$ sodium phosphate buffer followed by washing and serial dehydration using ethanol at increasing concentrations (i.e., 25$50 \%, 75-95 \%, 100 \%$ ) for $20 \mathrm{~min}$ each. This was followed by processing in propylene oxide for $20 \mathrm{~min}$ and then propylene oxide (PO) +EPON in $2: 1$ ration for $1 \mathrm{~h}$, followed by $\mathrm{PO}+\mathrm{EPON}$ (1:1) overnight. Each sample was then embedded in $100 \%$ EPON and baked at $65^{\circ} \mathrm{C}$ for $2 \mathrm{~d}$. Samples were sectioned at $70 \mathrm{~nm}$, stained with uranyl acetate and Sato's lead stain and then visualized under a Jeol (JEM-1400) transmission electron microscope. Images were recorded with an Advanced Microscopy Techniques V601 digital camera.

STORM. Stochastic optical reconstruction microscopy (STORM) imaging was performed on a custom built system as described previously (Suleiman et al., 2013). Cryosections were immunolabeled with primary 
A

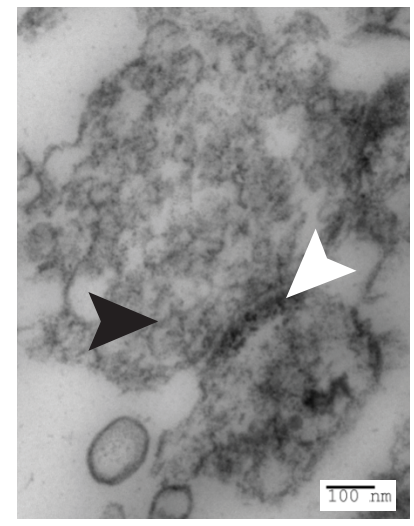

B

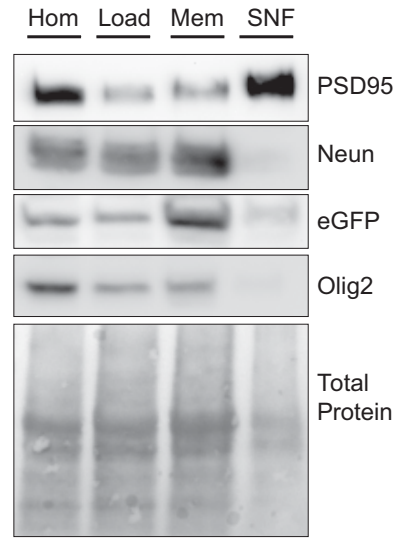

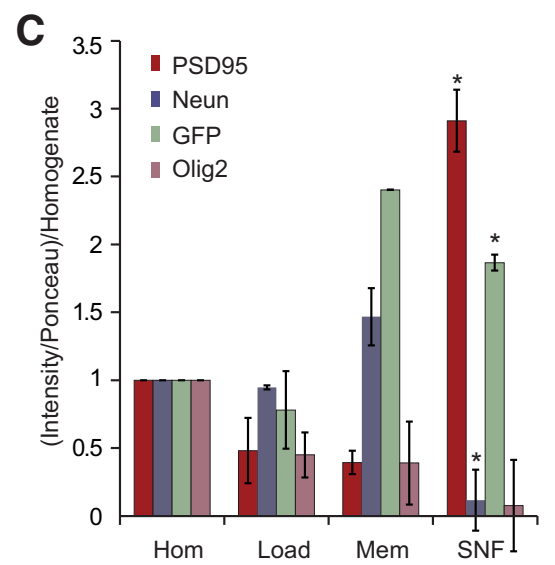

Figure 1. Synaptoneurosomal fractions. A, Electromicrograph of a synaptoneurosome, including presynaptic vesicles (black arrow) and postsynaptic density (white arrow), in the SNF. $B$, Representative immunoblots of a total forebrain Hom, supernatant that is the input to the discontinuous column (Load) after cell lysis, Mem, and SNF. C, Quantification of three replicate immunoblots reveals the expected relative enrichment of PSD-95 and depletion of OLIG2 and NeuN in the SNF relative to the homogenate and other fractions. eGFP/Rpl10a is also robustly detected. Each sample is normalized to Ponceau stain and corresponding homogenate. Error bars \pm SEM. Analysis by $t$ test with $4 \mathrm{df}$ of SNF samples compared with loading controls: GFP: $t=6.46, p=0.003$; PSD95: $t=12.67, p=0.0002 ; 0$ LIG2: $t=1.72, p=0.16 ;$ NeuN: $t=6.38, p=0.0031 .{ }^{*} p<0.05$.

antibodies, Chicken anti-GFP (Invitrogen), Mouse anti-Bassoon (Novus Biologicals), and Rabbit anti-Homer1 (Synaptic Systems) followed by anti-chicken, anti-rabbit, and anti-mouse secondary antibodies raised in donkey (Jackson ImmunoResearch). Secondary reagents were customconjugated with acceptor and reporter fluorophore dye pairs Cy3AlexaFluor 647, Cy2-AlexaFluor 647, and AlexaFluor 405-AlexaFluor 647. Immunolabeled sections were overlaid with a buffer containing $100 \mathrm{~mm}$ Tris- $\mathrm{HCl}$, pH8.0, $150 \mathrm{~mm} \mathrm{NaCl}$, and containing an oxygen scavenging system comprised of glucose, glucose oxidase, catalase, and the reducing agent 2-mercaptoethylamine. After removing excess buffer, edges of the coverslip were sealed with nail polish before imaging. Sparse single molecule images were acquired at $60 \mathrm{~Hz}$ frequency using an imaging and activator laser sequence: one frame of weak activator laser (561/ $488 / 405)$ followed by three frames of $642 \mathrm{~nm}$ laser at $560 \mathrm{~W} / \mathrm{cm}^{2}$, repeated as a train for each activator dye-antibody combination. The intensity of activation lasers was adjusted to ensure sparse single molecule events in each camera frame. Raw image stacks were analyzed to determine the centroid positions of fluorescent intensity peaks and these STORM localizations were rendered as images using custom software.

Western blot. Three independent SNF preparations were performed as described above. Samples were collected from total cortical dissection homogenate (Hom) in homogenization buffer, supernatant that is the input to the discontinuous column after cell lysis (load/loading control), the membrane fraction (Mem), and the SNF. Ten microliters of Hom, $10 \mu \mathrm{l}$ loading control, $30 \mu \mathrm{l} \mathrm{Mem}$, and $30 \mu \mathrm{l}$ of the SNF samples (diluted to $40 \mu \mathrm{l}$ ) were loaded onto a $4-12 \%$ polyacrylamide gel and semi-dry transferred to a PVDF membrane. Total protein was quantified using ImageJ software on the intensity of the Ponceau stain from 20 to $100 \mathrm{kda}$ on each sample. Individual proteins were probed using Mouse PSD-95 (1:1000; Enzo, VAM-PS002, RRID: AB_2039456), Mouse NeuN (1:500; Millipore Bioscience Research Reagents, MAB377, RRID: AB_2298772), Chicken GFP (1:1000; Aves, GFP-1020, RRID: AB_10000240), and Rabbit Olig2 (1:1000; Millipore Bioscience Research Reagents, AB 9610, RRID:AB_10141047). HRP secondaries (Bio-Rad) were used at 1:10,000. Blots were developed in Clarity Western ECL Substrate (Bio-Rad) for 5 min before imaging on a Thermo Scientific MyECL imager. ImageJ was used to quantify the pixel intensity of the protein band. This intensity was divided by the intensity of the total protein of the sample to correct for the amount of protein loaded onto the lane and normalized to the intensity of the homogenate. Analysis by $t$ test with $4 \mathrm{df}$ of SNF samples compared with loading controls.

Pathway and cell-type analysis. Pathway analysis for Figure $8 A, B$ was conducted with the BINGO (3.0.3) plugin for Cytoscape (2.8.2; Maere et al., 2005). A hypergeometric test with Benjamini-Hochberg multiple testing correction was implemented to detect over-represented catego- ries from GO_MF, GO_BP, and GO_CC. Highly similar results were found using NIH DAVID (Huang et al., 2009) against a background set of neuronal genes identified in the $\mathrm{WCH}>2 \mathrm{CPM}$, and displayed in Figure $8 C, D$.

Initial analysis of cellular sources of mRNA from the SNF was conducted with the cell-type-specific expression analysis (CSEA) tool as described, using the 150 most significantly enriched transcripts (Xu et al., 2014). Glial mRNAs were confirmed by downloading the Barres laboratory dataset (barreslab_rnaseq.xlsx) from http://web.stanford.edu/ group/barres_lab/brain_rnaseq.html. Although not limited to forebrain, this database is better age-matched to the current experiment than previous TRAP analysis and includes direct measures of microglial and endothelial mRNAs. To identify transcripts significantly enriched in each cell type, we used the specificity index algorithm (Dougherty et al., 2010) with default settings except a p_max cutoff of pSI $<0.01$.

CSEA was additionally applied to SNF mRNA using single-cell transcriptomic profiling data from mouse cortex (Zeisel et al., 2015). Raw mRNA count data was downloaded from http://linnarssonlab.org/cortex/. Counts were incremented by a pseudo-count of 1 and then reads per kilobase million-normalized. RPKMs were averaged over each of the 47 cell subclasses identified by the authors using the BackSPIN clustering algorithm. Significantly enriched transcripts in each subclass were identified using the SI algorithm with a minimum expression value of 6 RPKM and default settings otherwise.

Sequence feature analysis. Analysis of sequence length, GC content, and predicted RNA secondary structure stability was performed on the longest protein-coding isoform of each gene with annotated 5' and 3' UTRs, as determined from Ensembl v75 annotation data retrieved using the biomaRt package in R. Filtering for protein coding sequences with annotated UTRs resulted in the elimination of 11 genes from feature analysis, resulting in $n=457$ total genes (146 local translation candidates, 311 somatic translation candidates). For statistical analysis, sequence length was $\log 2$-transformed to achieve a normal distribution. RNA secondary structure stability of UTRs was predicted using ViennaRNA RNAfold program (Lorenz et al., 2011), which computes the minimum-free energy secondary structure of each sequence. Free energy values were then normalized by sequence length, and multiplied by -1 to give a positive index of RNA structure stability in the UTR. Comparisons of somatic and local translation candidates were performed using Welch's $t$ test with Benjamini-Hochberg multiple testing $(\mathrm{BH})$ correction.

Overlap analyses. FMRP targets were downloaded from table S2 of (Darnell et al., 2011), subsetted to those with $p<0.01$ in their data, and tested for overlap with a one-tailed Fisher's exact test. To confirm this result was not driven by the known length or expression biases, 1000 random gene sets, sampled to match the FMRP list for transcript length 


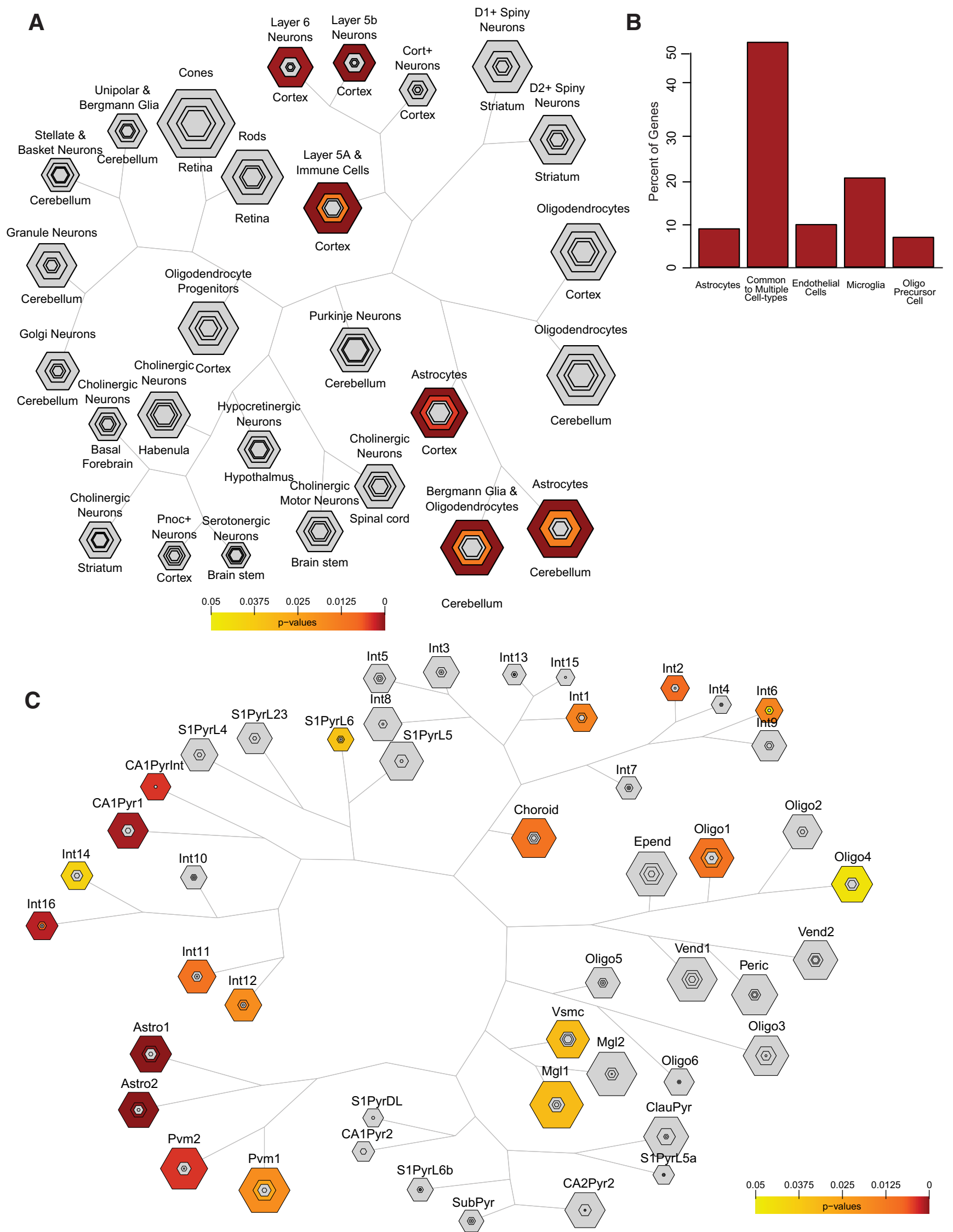

Figure 2. Cell-type enrichment in the SNF. A, CSEA analysis using TRAP reference gene sets of top 150 SNF transcripts (for full list, see Fig. 2-1 available at https://doi.org/10.1523/JNEUROSCI. 3044-16.2017.f2-1) indicates significant enrichment of mRNAs expressed in adult cortical neurons (Pnoc, Layer 6b), but also some mRNAs expressed in glial cell types (astrocytes, and the Etv1 line which measured both pyramidal neurons and putative microglia). Polygon size is scaled to number of genes enriched in each cell type, from least stringent (Figure legend continues.) 
and expression biases as described previously (Ouwenga and Dougherty, 2015), were also analyzed. True $p$ value exceeded significance of all 1000 permuted $p$ values. Constrained genes were from Lek et al. (2016, their supplemental Table 13). Other gene lists were from Lein et al. (2007, their supplemental Table 4), Ainsley et al. (2014, their supplemental Table 2), and Cajigas et al. (2012, their supplemental Table 10). In each case gene lists were filtered to consider only those transcripts that were robustly measurable in the WCH $(\mathrm{CPM}>2)$.

Motif enrichment analysis. Multiple Em for Motif Elicitation (MEME; Bailey and Elkan, 1994) was used to identify overrepresented 3' UTR sequence motifs in local translation candidates and somatic translation candidates. One 3' UTR from each candidate list was removed due to prohibitively short sequence length $(<15 \mathrm{nt})$. The MEME tool was run with the following parameters: zero or one occurrences per sequence, min width $=6$, max width $=50$, min no. sites $=16$, $\max$ no. motifs $=20$. The motif search was run in both normal mode and discriminative mode. In discriminative mode, local translation candidates were scanned using the somatic translation candidates as background, and vice versa. Enrichment of G-quadruplex motifs in local translation candidates and polyadenylation [poly(A)] signals in somatic translation candidates was further verified using the stringr package in $\mathrm{R}$ to count occurrences of regular expression matches to $\mathrm{G}_{3+} \mathrm{N}_{1-7} \mathrm{G}_{3+} \mathrm{N}_{1-7} \mathrm{G}_{3+} \mathrm{N}_{1-7} \mathrm{G}_{3+}$ and AATAAA, respectively.

Alternative splicing analysis. Alternative splicing analysis was conducted in MISO (v0.5.3; Katz et al., 2010). RNA-seq reads, filtered as described above, were aligned to the $\mathrm{mm} 9$ mouse genome (Ensembl v67) using STAR. Percentage spliced in $(\Psi)$ values were calculated for each sample by running MISO on each alignment file using version 1 of the exon-centric $\mathrm{mm} 9$ alternative splicing events compiled by Wang et al. (2008). All alternative event types available in the annotation were analyzed: alternative $3^{\prime}$ splice sites (A3SS), alternative $5^{\prime}$ splice sites (A5SS), alternative first exons (AFE), alternative last exons (ALE), mutually exclusive exons (MXE), retained introns (RI), skipped exons (SE), and tandem UTRs (TandemUTR).

All downstream processing and analysis of MISO output was conducted in R. Alternative splicing events were filtered by requiring that events meet the following coverage criteria for at least 9 of 12 samples: at least 10 reads supporting both isoforms, with at least one read supporting the exclusion isoform. Samples were assessed for differential $\Psi(\Delta \Psi)$ analogously to the differential expression analysis described above, using a permuted $t$ test with 5000 iterations. Similar to the definition of local translation candidates, neurite-enriched alternative splicing events were defined as the set of events with significantly altered $\Psi(p<0.05)$ in both SNF versus WCH and SynapTRAP versus SNF comparisons (Fig. 10-1 available at https://doi.org/10.1523/JNEUROSCI.3044-16.2017.f10-1). Somaenriched alternative splicing events were defined analogously (Fig. 10-2 available at https://doi.org/10.1523/JNEUROSCI.3044-16.2017.f10-2). For analysis of global trends in $\Delta \Psi$ between samples, alternative splicing events were filtered down to those located in genes identified as confidently expressed in neurons, based on TRAP/WCH ratios of negative control genes as described previously (Dougherty et al., 2010), but were not filtered based on $\Delta \Psi p$ value.

Experimental design and statistical analysis. All statistical tests are reported in the Material and Methods section for each experiment. The design, sample sizes, intermediate values, and results can be found in the legend of each figure in which they are represented. The SynapTRAP preparations, Western blot, electron microscopy, and quantitative PCR

$\leftarrow$

(Figure legend continued.) threshold (outermost polygon), to most stringent threshold (innermost polygon) for identifying cell-type-specific genes. Color indicates significance of overlap per provided scale bar. Gray indicates $p>0.05 . \boldsymbol{B}$, Comparison of the 100 most enriched SNF transcripts to the Barres laboratory P21 RNA-sequencing dataset also reveals that although $>50 \%$ of transcript are found in multiple neural cell types (including neuron), a substantial number of transcripts are likely derived specifically from glial cell populations. C, CSEA using single-cell reference gene sets on the top 100 SNF transcripts confirms contribution of both neuronal (Int1,2,6,11,12,14,16, Ca1Pyr1, CA1Pyrlnt, S1PyrL6) and non-neuronal (e.g., Oligo1, Astro1,2, Pvm1,2, Mgl1, Vsmc) sources to SNF transcripts.
(qPCR) were performed with both sexes pooled in each column. ISH replication used only male mice. All data are available at GEO: GSE74506.

\section{Results}

\section{Synaptoneurosomal fractionation enriches for processes and mRNAs of multiple cell types}

We first sought to determine the mRNA composition of a SNF using a classic biochemical technique to harvest membrane enclosed pre- and postsynaptic positions (Westmark et al., 2011). SNFs previously have been shown to be competent for translation by incorporation of radiolabeled methionine (Westmark et al., 2011). They have also been show to contain mRNA detectably by qPCR (Meyer-Luehmann et al., 2009), suggesting they may be amenable to RNA-seq analysis. Examination of our SNF with electron microscopy confirmed that the sample contained synaptoneurosomes (Fig. 1A), and immunoblots showed the expected enrichment for the synaptic marker PSD-95, and depletion of the neuronal nuclear marker NeuN and glial nuclear marker Olig2 (Fig. $1 B, C$ ). We then optimized a method for RNA purification from SNFs. Three replicate samples of both the SNF and the starting cortical WCH were analyzed by high throughput RNAsequencing. Overall, 3408 transcripts were found to be significantly enriched by this fractionation (Fig. 2-1 available at https:// doi.org/10.1523/JNEUROSCI.3044-16.2017.f2-1). Examination with CSEA (Xu et al., 2014) suggested the SNF is enriched in mRNAs expressed in both neuronal and glial cell types from adult cortex (Fig. 2A). To confirm this, we also used the Barres laboratory RNA-sequencing database (Zhang et al., 2014). This confirmed that almost $40 \%$ of the top SNF enriched transcripts were specifically expressed in various types of glia (Fig. $2 B$ ). Both the Barres (Zhang et al., 2014) and original Xu et al. (2014) analyses had limited numbers of subtypes of cells available. Therefore, we updated CSEA using as a foundation a newer single-cell RNA-seq profiling from mouse forebrain (Zeisel et al., 2015). Using this more fine-grained view of cell types, we confirmed transcripts enriched in multiple types of neurons and glia are detected in the SNF (Fig. 2C). Thus, although SNFs enrich for a subpopulation of transcripts that include those known to be localized to dendrites of hippocampus, such as CaMKII $a$ (Burgin et al., 1990; 2.19 fold-change, $p=0.028)$, mRNA from additional cell types is enriched in the SNF as well.

\section{Tagged ribosomes localize to processes in many neuronal cell types across the CNS}

Ribosomes have long been observed near synapses by electron microscopy (Steward and Levy, 1982) and are observable in transgenic mice via GFP expression. Previously, we generated dozens of "bacTRAP" mouse lines which express eGFP/Rpl10a in a wide variety of neuronal types for cell-type-specific translational profiling (Doyle et al., 2008; Dougherty et al., 2012, 2013; Dalal et al., 2013). While characterizing these lines we noticed that eGFP/ Rpl10a, which predominantly filled the soma, also extended more weakly but consistently into processes connected to the cell bodies (Fig. 3). Higher-resolution confocal analyses confirmed GFP-positive puncta throughout the dendrites of Purkinje cells (Fig. 3B). To validate that this pattern was not unique to Purkinje cells, we also imaged a bacTRAP line (Slc6a4-eGFP/Rpl10a; Dougherty et al., 2013; Fig. 3C-E) labeling midbrain serotonin neurons. Dendrites of these neurons are also sufficiently sparse to enable super-resolution analyses of individual processes. STORM revealed eGFP/Rpl10a extending into the dendrites and localizing in puncta within $<1 \mu \mathrm{M}$ of synapses as defined by apposition of presynaptic and postsynaptic markers (Dani et al., 2010). 
Thus, the eGFP ribosomal fusion protein is localized to neurites and near synapses.

\section{SynapTRAP: a strategy for mRNA isolation from the processes of cortical neurons}

Because the eGFP/Rpl10a fusion proteins localize to neurites, using TRAP on the SNF could produce a sample enriched for local mRNAs on neuronal ribosomes. We first confirmed by immunoblots that the SNF clearly contains eGFP/Rpl10a (Fig. $1 B, C)$. We used the Snap25-eGFP/Rpl10a line, which labels all cortical neurons (Dougherty et al., 2012), and isolated four RNA sample types from a cortical dissection (Fig. 4): WCH before and after affinity purification (i.e., standard "whole-cell" TRAP) and the SNF before and after affinity purification (SynapTRAP). Bioanalyzer analysis of each confirmed that high quality RNA is present in the SNF. In addition, robust detection of the 18S rRNA (which is only in the small subunit), after SynapTRAP capture affinity purification of eGFP-Rpl10a (which is on the large subunit), indicates we captured intact $80 \mathrm{~S}$ ribosomes: the large subunit does not engage the small subunit until initiation of translation (Fig. 4B). This indicates that the SynapTRAP method is able to collect ribosome-bound mRNA from the SNF. We then sequenced the RNA from all four sample types. All four conditions showed good alignment rates: at least $74 \%$ of reads mapped uniquely after read trimming and rRNA removal. Greater than $86 \%$ of mapped reads were exonic (Fig. $4 C$ ).

First, we examined the distributions of the log2 "fold-changes" when comparing WCH to the SNF, as well as the SynapTRAP/SNF and TRAP/WCH (Fig. 5A). The distribution of the SNF/WCH comparison was markedly bimodal, with a subset of the $>3400$ transcripts showing robust enrichment in the SNF. Enrichment by TRAP from WCH was unimodal, as expected from prior studies. TRAP compared with input from the SNF fraction was also unimodal, though it is worth noting that the range of the distribution in the SynapTRAP/SNF comparison is attenuated compared with the TRAP/WCH distribution and enrichment of neuronal genes and depletion of glial genes is less robust in the SynapTRAP/SNF comparison. Quantifying this specifically (Fig. 5B), known glial genes are significantly depleted relative to known neuronal genes in both comparisons $(p<2.2 \mathrm{E}-16$ and $p<0.0001$, Welch's $t$ tests), as expected, though with substantially lower magnitude in SynapTRAP/ SNF (difference in mean log2 fold-change:
A

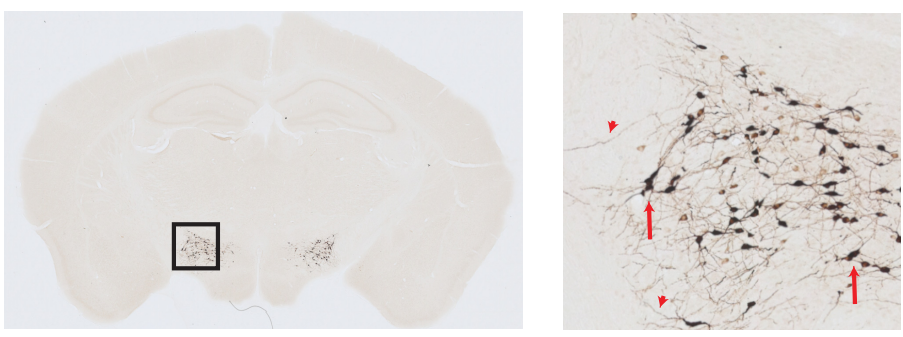

B

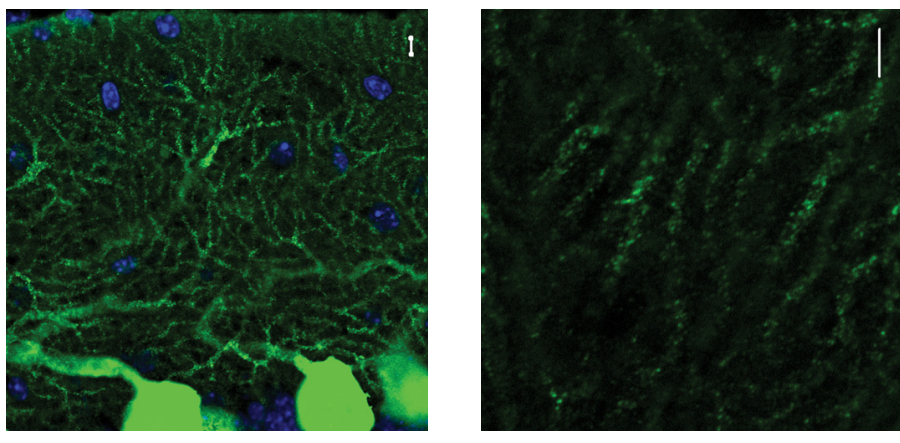

C

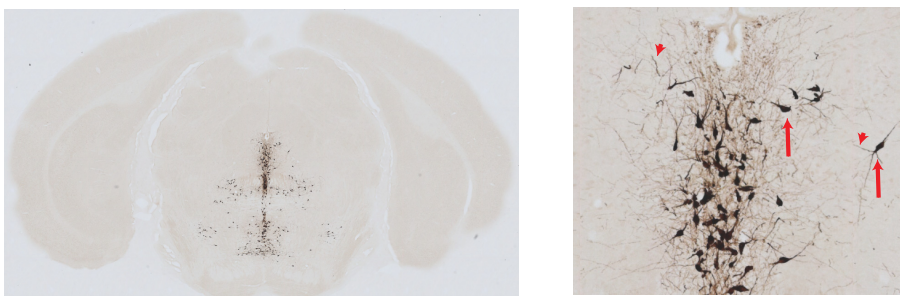

D
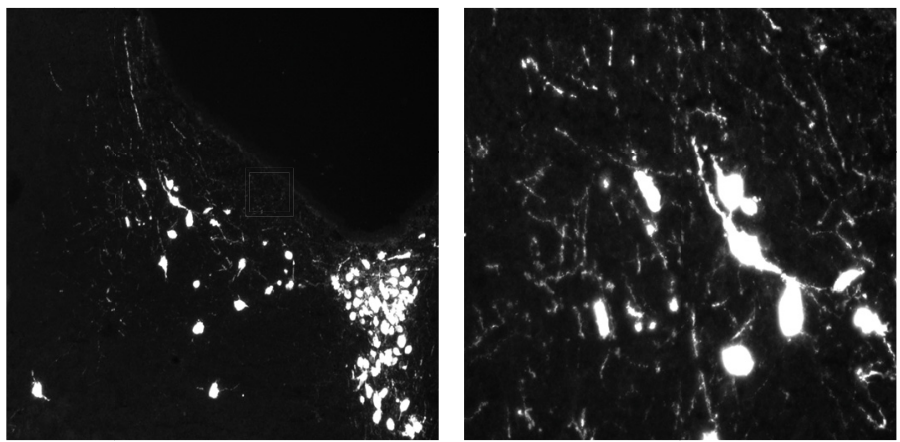

E
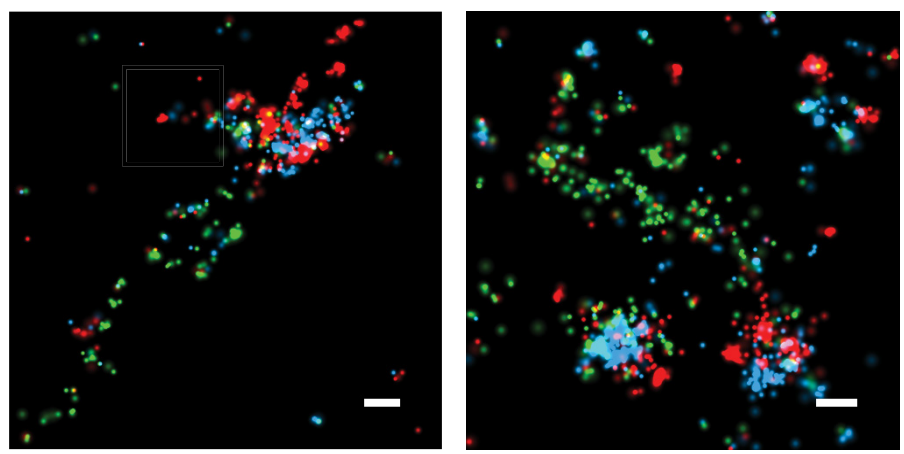

Figure 3. eGFP/Rpl10a is found in neurites across multiple bacTRAP lines. $\boldsymbol{A}$, Anti-GFP immunohistochemistry on hypocretinergic line Hcrt-eGFP/Rpl10a shows labeling of neuronal cell bodies and large caliber fibers (presumptive dendrites) in the lateral hypothalamus. $B$, Anti-GFP immunofluorescence of Pcp2-eGFP/Rpl10a reveals eGFP/Rpl10a is found in discrete puncta along the dendrites in the Purkinje cell layer of the cerebellum. Scale bars, $5 \mu$ m. C, Serotonergic line Slc6a4-eGFP/Rpl10a shows labeling of neuronal cell bodies and large caliber fibers (presumptive dendrites) in the Raphe nuclei. D, Immunofluorescence of SIc6a4-eGFP/ Rpl10a reveals punctate labeling in large caliber processes extending from cell bodies. $\boldsymbol{E}$, STORM microscopy reveals these GFPpositive puncta (green) within the processes are proximal to glutamatergic synapses, as defined by apposition of bassoon (red) and homer (blue). Scale bars, $200 \mathrm{~nm}$. 

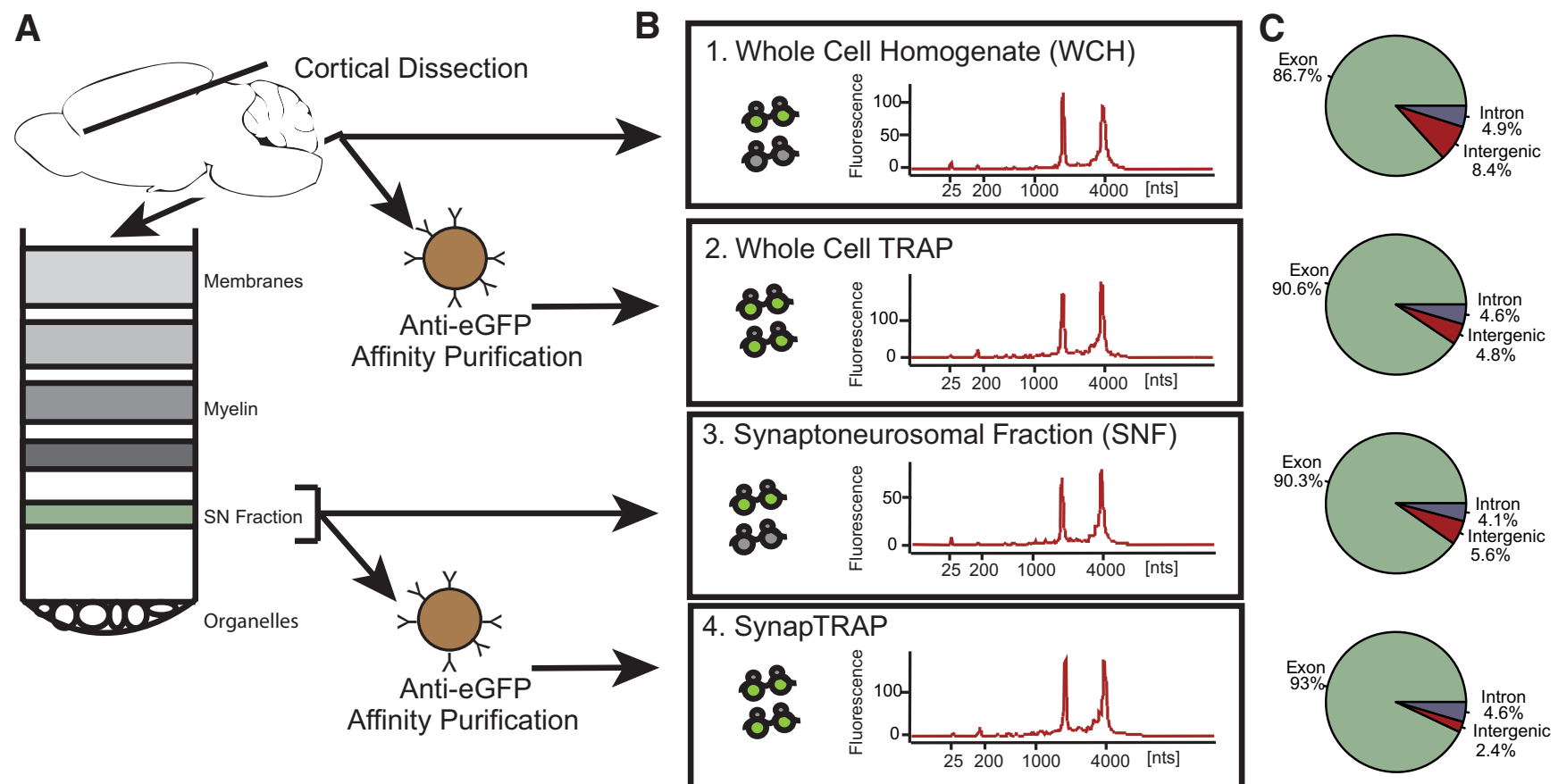

Figure 4. SynapTRAP method for isolating localized translation in neuronal projections. $\boldsymbol{A}$, Workflow of RNA isolation from cortical samples and ( $\boldsymbol{B}$ ) the four RNA samples collected by the method. Representative RNA bioanalyzer traces demonstrate the harvest of intact 80 S ribosomes, indicated by both large (28S) and small subunit (185) ribosomal capture. $\boldsymbol{C}$, Percentage of reads that map to exons, introns, and intergenic regions. Greater than $86 \%$ reads mapped to exons across all sample types.

$0.11)$ than standard TRAP/WCH (0.96). Therefore, we conservatively focused downstream analyses only on the most significantly enriched transcripts in either comparison.

A comparative analysis from these four conditions was used to generate two lists. First, to identify candidates for local translation, we selected transcripts that were enriched by both TRAP and cellular fractionation (local translation candidates; Fig. 5C). Second, as a comparison group, we identified candidates sequestered to the somatic region (somatic translation candidates; Fig. 5D) by selecting transcripts that were neuronal (i.e., enriched by TRAP/WCH) but relatively depleted in the SNF/WCH. This highlighted 153 local translation candidates and 315 somatic translation candidates with high confidence for further analysis (Figs. 5-2 and 5-3 available at https://doi. org/10.1523/JNEUROSCI.3044-16.2017.f5-2 and https://doi.org/ 10.1523/JNEUROSCI.3044-16.2017.f5-3, respectively).

Reassuringly, the high confidence local translation candidates included mRNAs known to localize in neuronal processes in other brain regions such as Arc, Shank3, and CamkIIa (Burgin et al., 1990; Epstein et al., 2014; Steward et al., 2014). The candidates also overlap with several previous studies of localized translation. The local translation candidates overlap significantly (Fig. 5E) with hippocampal neuropil transcripts studied by microdissection and RNA-seq ( $p<0.014$, Fisher's exact test; Cajigas et al., 2012), microdissection combined with TRAPseq $(p<2.5 \mathrm{E}-11$; Ainsley et al., 2014), and in situ hybridization ( $p<0.0002$; Lein et al., 2007), but not a recent study of axonal transcripts in the adult and postnatal day 7 retinal-thalamic projection $(p<0.25$; Shigeoka et al., 2016). The list also included novel candidates such as Brsk1, which codes for a protein involved in the polarization of cortical neurons. This kinase has a nuclear role involved in DNA damage repair, but the protein also localizes to synapses for a secondary role in which it mediates the phosphorylation of microtubule associated proteins and aids in neurotransmitter release (Lu et al., 2004; Inoue et al., 2006; Müller et al., 2010; Yoshida and Goedert, 2012). Interestingly, we also observed sev- eral other transcriptional regulators in our list of local translation candidates, consistent with a prior report (Ainsley et al., 2014). These additional mRNAs may indicate the existence of signaling pathways that employ spatial control of translation to regulate nuclear functions. Alternatively, some of these proteins, like BRSK1, may have a secondary role at the synapse (Bright et al., 2008). SynapTRAP is a viable way to select candidates such as these for further experimentation. Here we focused first on validation of this new method with established assays, followed by computational analyses to identify pathways and features of transcripts most enriched in local translation.

\section{Validation of local translation candidates with independent methods}

First, to confirm reproducibility of the RNA-sequencing results, qPCR analysis was performed on three additional independent replications. The results validated both the increased abundance of local translation candidates (Fig. 6A) and decreased abundance of somatic translation candidates (Fig. $6 B$ ) in the SynapTRAP samples. Positive and negative controls from previous hippocampal studies (Cajigas et al., 2012; Ainsley et al., 2014) were also included and showed the expected changes (Fig. 6C).

Next, to verify the existence of these mRNAs in the processes of neurons in vivo, several local translation candidates were analyzed using FISH. To identify single neurites among the densely interwoven neurons of the cortex, $\mathrm{Tg}$ (Thyl-EGFP) $\mathrm{M}^{\mathrm{Jrs} / \mathrm{J}}$ mice were used as they sparsely label cortical neurons in vivo. Each local translation candidate showed hybridization signal in GFP labeled neurites (Fig. 7) significantly more than no probe controls. In contrast, analysis of a somatic candidate, Hist $3 h 2 b a$, did not significantly differ from no probe controls in the number of puncta in neurites, despite a robust FISH signal present proximal to DAPI nuclei stain of adjacent cells. This suggests that Hist $3 h 2 b a$ is sequestered to the somatic region and local transla- 
A

SNF/WCH Distribution

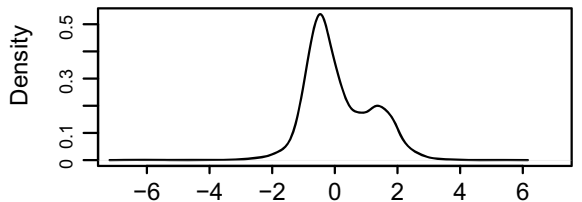

B

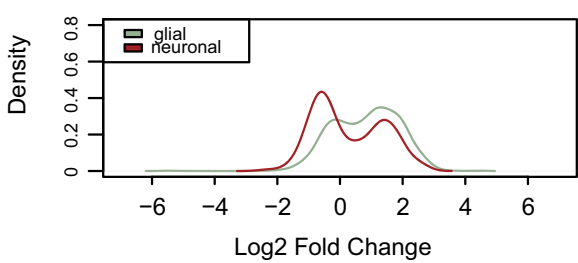

TRAP/WCH Distribution
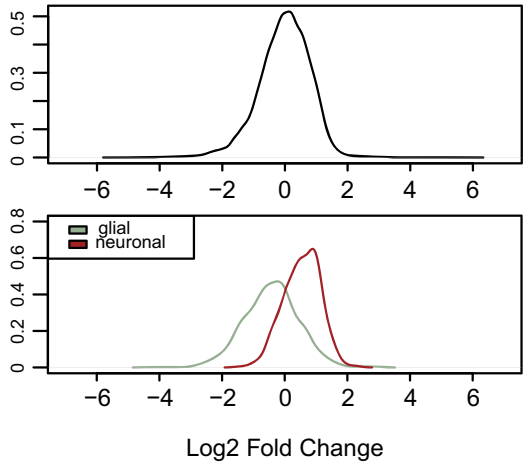

SynapTRAP/SNF Distribution
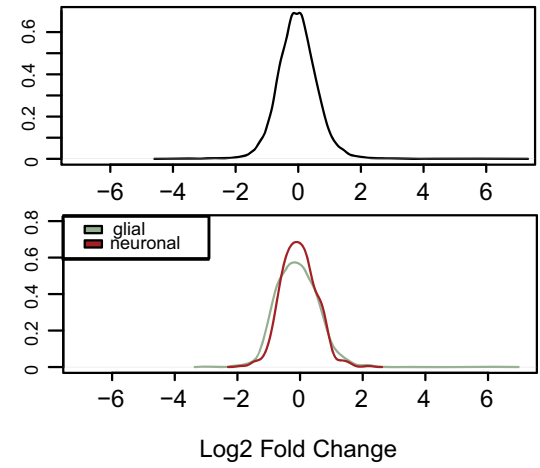

C

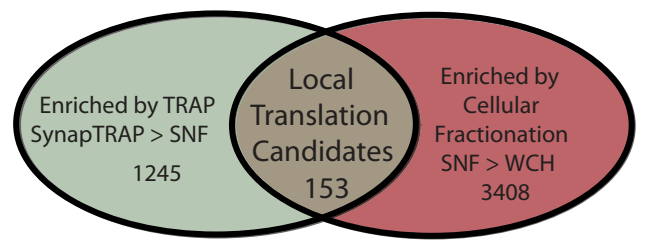

Enrichment by

Cellular Fractionation

Local Translation Candidates

Enrichment by TRAP SynapTRAP > SNF

SNF $>$ WCH

\begin{tabular}{|l|l|r|r|r|r|r|r|}
\hline Gene ID & Gene Name & LogFC & Pvalue & FDR & LogFC & Pvalue & FDR \\
\hline ENSMUSG00000022602 & Arc & 1.23 & $8.63 \mathrm{E}-04$ & $2.36 \mathrm{E}-02$ & 0.80 & $2.81 \mathrm{E}-02$ & $7.00 \mathrm{E}-02$ \\
\hline ENSMUSG00000035390 & Brsk1 & 1.42 & $8.42 \mathrm{E}-07$ & $2.51 \mathrm{E}-04$ & 0.96 & $1.21 \mathrm{E}-03$ & $5.40 \mathrm{E}-03$ \\
\hline ENSMUSG00000024617 & Camk2a & 1.35 & $4.80 \mathrm{E}-03$ & $7.04 \mathrm{E}-02$ & 1.14 & $1.71 \mathrm{E}-02$ & $4.75 \mathrm{E}-02$ \\
\hline ENSMUSG00000026879 & Gsn & 1.58 & $2.73 \mathrm{E}-02$ & $1.82 \mathrm{E}-01$ & 2.19 & $2.80 \mathrm{E}-03$ & $1.09 \mathrm{E}-02$ \\
\hline ENSMUSG00000038437 & Mllt6 & 1.39 & $6.66 \mathrm{E}-05$ & $4.87 \mathrm{E}-03$ & 1.38 & $7.91 \mathrm{E}-05$ & $5.22 \mathrm{E}-04$ \\
\hline ENSMUSG00000030739 & Myh14 & 1.96 & $2.80 \mathrm{E}-05$ & $2.65 \mathrm{E}-03$ & 1.30 & $6.53 \mathrm{E}-03$ & $2.18 \mathrm{E}-02$ \\
\hline ENSMUSG00000006435 & Neurl1a & 1.56 & $2.94 \mathrm{E}-06$ & $6.27 \mathrm{E}-04$ & 0.99 & $3.08 \mathrm{E}-03$ & $1.17 \mathrm{E}-02$ \\
\hline ENSMUSG00000006476 & Nsmf & 1.44 & $3.06 \mathrm{E}-06$ & $6.33 \mathrm{E}-04$ & 1.13 & $2.19 \mathrm{E}-04$ & $1.26 \mathrm{E}-03$ \\
\hline ENSMUSG00000022623 & Shank3 & 1.50 & $1.42 \mathrm{E}-05$ & $1.63 \mathrm{E}-03$ & 1.36 & $7.69 \mathrm{E}-05$ & $5.09 \mathrm{E}-04$ \\
\hline ENSMUSG00000027457 & Snph & 1.25 & $1.12 \mathrm{E}-05$ & $1.41 \mathrm{E}-03$ & 1.05 & $2.12 \mathrm{E}-04$ & $1.22 \mathrm{E}-03$ \\
\hline
\end{tabular}

E

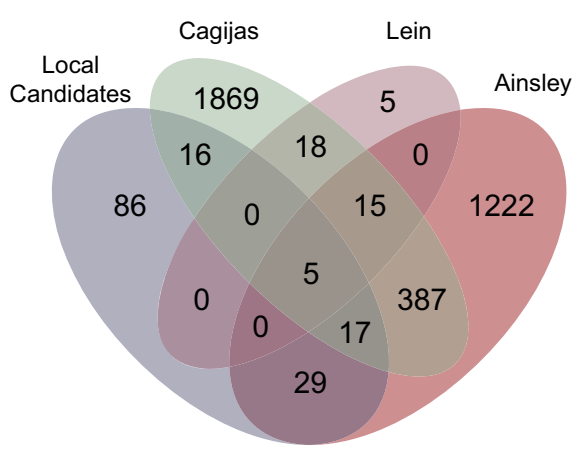

D

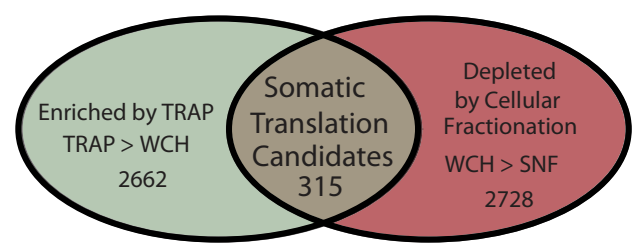

Enrichment by TRAP TRAP $>$ WCH
Depletion by Cellular Fractionation WCH $>$ SNF

Somatic Translation Candidates
\begin{tabular}{|l|l|r|l|l|l|l|l|}
\hline & \multicolumn{3}{c}{ TRAP $>$ WCH } \\
\hline Gene ID & Gene Name & LogFC & Pvalue & FDR & LogFC & Pvalue & FDR \\
\hline ENSMUSG00000057649 & Brd9 & 0.81 & $2.86 \mathrm{E}-03$ & $1.64 \mathrm{E}-02$ & -0.64 & $2.94 \mathrm{E}-02$ & $7.25 \mathrm{E}-02$ \\
\hline ENSMUSG00000022212 & Cpne6 & 1.38 & $3.09 \mathrm{E}-10$ & $7.05 \mathrm{E}-08$ & -0.69 & $2.46 \mathrm{E}-03$ & $9.78 \mathrm{E}-03$ \\
\hline ENSMUSG00000024560 & Cxxc1 & 0.84 & $5.55 \mathrm{E}-04$ & $4.78 \mathrm{E}-03$ & -0.79 & $4.36 \mathrm{E}-03$ & $1.57 \mathrm{E}-02$ \\
\hline ENSMUSG00000056895 & Hist3h2ba & 1.12 & $2.13 \mathrm{E}-03$ & $1.31 \mathrm{E}-02$ & -0.92 & $4.54 \mathrm{E}-02$ & $1.02 \mathrm{E}-01$ \\
\hline ENSMUSG00000003500 & Impdh1 & 1.04 & $2.75 \mathrm{E}-05$ & $4.86 \mathrm{E}-04$ & -0.83 & $5.37 \mathrm{E}-03$ & $1.85 \mathrm{E}-02$ \\
\hline ENSMUSG00000046432 & Ngfrap1 & 1.25 & $3.16 \mathrm{E}-08$ & $2.60 \mathrm{E}-06$ & -0.71 & $2.37 \mathrm{E}-03$ & $9.48 \mathrm{E}-03$ \\
\hline ENSMUSG00000021645 & Smn1 & 0.98 & $3.70 \mathrm{E}-03$ & $1.98 \mathrm{E}-02$ & -1.53 & $1.33 \mathrm{E}-03$ & $5.83 \mathrm{E}-03$ \\
\hline ENSMUSG00000052293 & Taf9 & 1.36 & $1.49 \mathrm{E}-06$ & $5.15 \mathrm{E}-05$ & -0.90 & $5.24 \mathrm{E}-03$ & $1.82 \mathrm{E}-02$ \\
\hline ENSMUSG00000029359 & Tesc & 1.51 & $8.29 \mathrm{E}-08$ & $5.56 \mathrm{E}-06$ & -0.80 & $1.14 \mathrm{E}-02$ & $3.43 \mathrm{E}-02$ \\
\hline ENSMUSG00000036989 & Trim3 & 0.70 & $3.08 \mathrm{E}-03$ & $1.73 \mathrm{E}-02$ & -0.76 & $3.03 \mathrm{E}-03$ & $1.16 \mathrm{E}-02$ \\
\hline
\end{tabular}

Figure 5. Comparative analysis to define local translation candidates for cortical neurons. $\boldsymbol{A}$, Distributions of Log2 fold-changes for three pairwise comparisons (Fig. 5-1 available at https://doi. org/10.1523/JNEUROSCI.3044-16.2017.f5-1). B , Distributions of Log2 fold-changes for same comparisons highlighting those implicated in a prior study (Dougherty et al., 2012) as neuron or astrocyte derived. C, The candidate lists were generated by the overlap of differentially detected transcripts in the samples. Local translation candidates (Fig. 5-2 available at https://doi.org/10. 1523/JNEUROSCI.3044-16.2017.f5-2) were defined as those that were enriched in the SNF from the WCH (in cell processes) and also enriched in the SynapTRAP (Figure legend continues.) 


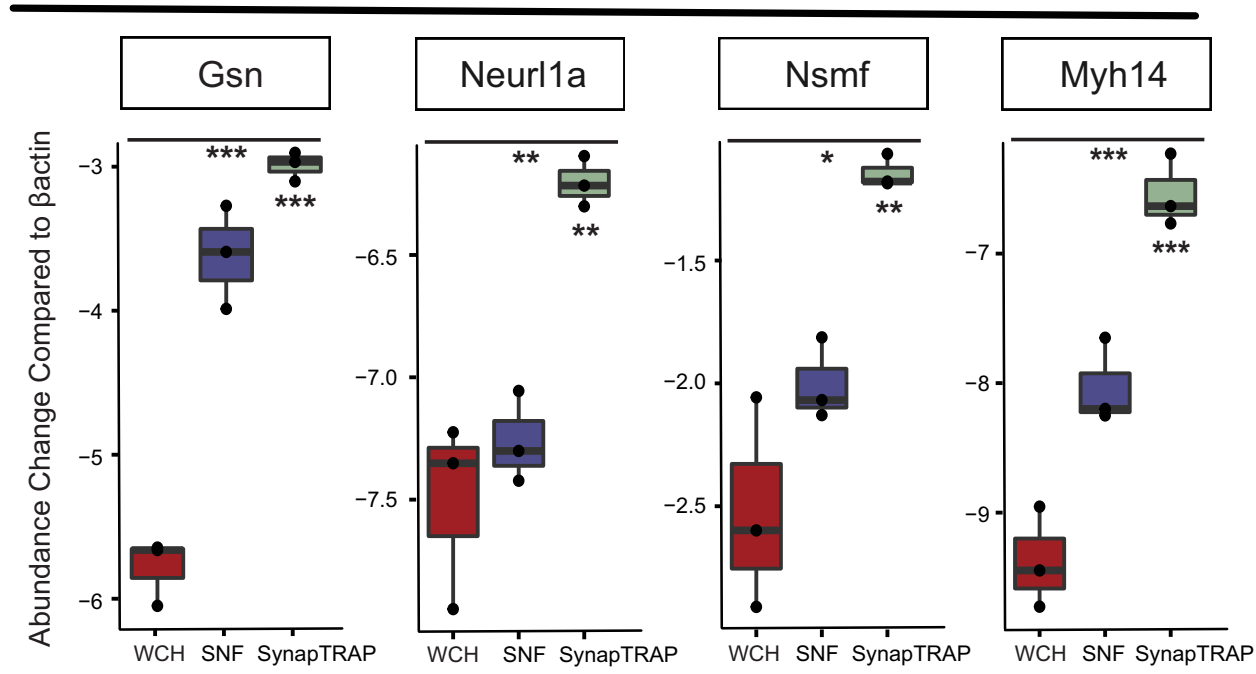

\section{B Somatic Translation Candidates C Controls}
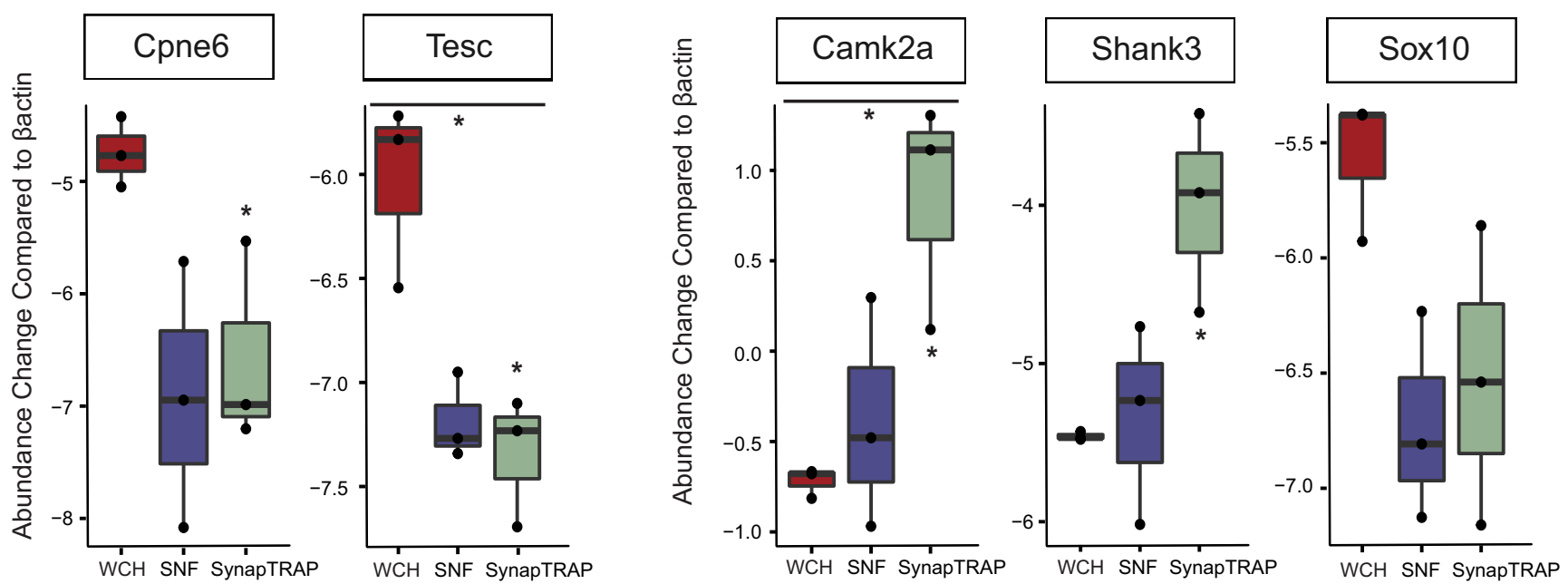

Figure 6. Validation by $q P C R$. $q P C R$ of the WCH, the traditional method of harvesting neurites (SNF), and the SynapTRAP sample of $(\boldsymbol{A})$ local translation candidates, $(\boldsymbol{B})$ somatic translation candidates, and (C) RNA previously described as localizing to neurites (Camk2a, Shank3) or the soma (Sox10). ${ }^{*} p<0.05,{ }^{* *} p<0.01,{ }^{* * *} p<0.001$ Statistical testing was determined by ANOVA (bar): Camk2a: $F=5.5, p=0.048 ;$ Shank3: $F=4.2, p=0.076 ;$ Sox10: $F=4.18, p=0.078 ;$ Armc6: $F=4.15, p=0.079 ;$ (pne6: $F=3.48, p=0.11 ; G s n: F=134.9, p=3.3 E-5 ;$ Myhl14: $F=$ 35.8, $p=0.00083$; Neurl1a: $F=12.6, p=0.009 ;$ Nsmf: $F=11.8, p=0.01 ;$ Tesc: $F=8.01, p=0.02$; and unpaired two-tailed $t$ test between WCH and SynapTRAP samples with $4 \mathrm{df}:$ Camk2a: $t=4.23, p=0.01 ;$ Shank3: $t=3.98, p=0.016 ;$ Sox10: $t=2.29, p=0.08$; Armc6: $t=4.16, p=0.04 ;$ Cpne6: $t=3.29, p=0.03 ;$ Gsn: $t=19.35, p=0.0001 ;$ Myhl14: $t=10.2, p=0.0005$; Neurl1a: $t=5.66, p=0.0048 ;$ Nsmf: $t=5.47, p=0.0054 ;$ Tesc: $t=4.17, p=0.0141$.

tions candidates colocalize with neurites as predicted from RNAsequencing results.

Pathway analysis highlights morphological regulation As a final validation of the method, we turned to informatics approaches. We reasoned that if SynapTRAP is successfully enriching$$
\leftarrow
$$

(Figure legend continued.) sample above the SNF (neuronal). Ten representative transcripts shown from the local translation candidates. D, Somatic translation candidates (Fig. 5-3 available at https://doi.org/10.1523/JNEUROSCI.3044-16.2017.f5-3) were defined as those that were depleted on the column compared with the WCH (not in processes) and enriched in the whole-cell TRAP above the WCH (neuronal). Ten representative transcripts from the somatic translation candidates. $\boldsymbol{E}$, Venn diagram of previous studies that overlap with the local translation candidates; Fisher's exact test, Cajigas: $p=0.01345, \mathrm{Cl}=(1.12, \mathrm{Inf}), \mathrm{OR}=1.56$; Ainsley: $p=2.692 \mathrm{E}-11, \mathrm{Cl}=(112.59, \mathrm{Inf}), \mathrm{OR}=3.5$; Lein: $p=0.000128, \mathrm{Cl}=(4.30, \mathrm{Inf}), \mathrm{OR}=11.6$. for locally translated transcripts, these should be (1) enriched in functional terms expected to occur in neurites and (2) have detectable sequence features that might mediate their peripheral translation. Thus, we first conducted a comparative pathway analysis of the two candidate lists, and then tested the hypothesis that there are sequence features which distinguish these two sets of genes, assessing both predicted and empirically detected binding motifs for proteins and RNA.

Examination of the local translation candidates highlighted several pathway enrichments (Fig. $8 A, C$ ). As expected there was significant enrichment of synapse $(p=6.14 \mathrm{E}-07)$, axon $(p=$ $2.04 \mathrm{E}-3)$, dendrite (0.030), postsynaptic density (2.53E-05), and other neuronal projection related terms (Fig. $8 \mathrm{C}$ ). Additionally, there was a clear enrichment of pathways related to cytoskeleton, motors, and junctions of cells. As $\beta$-actin mRNA has long been 

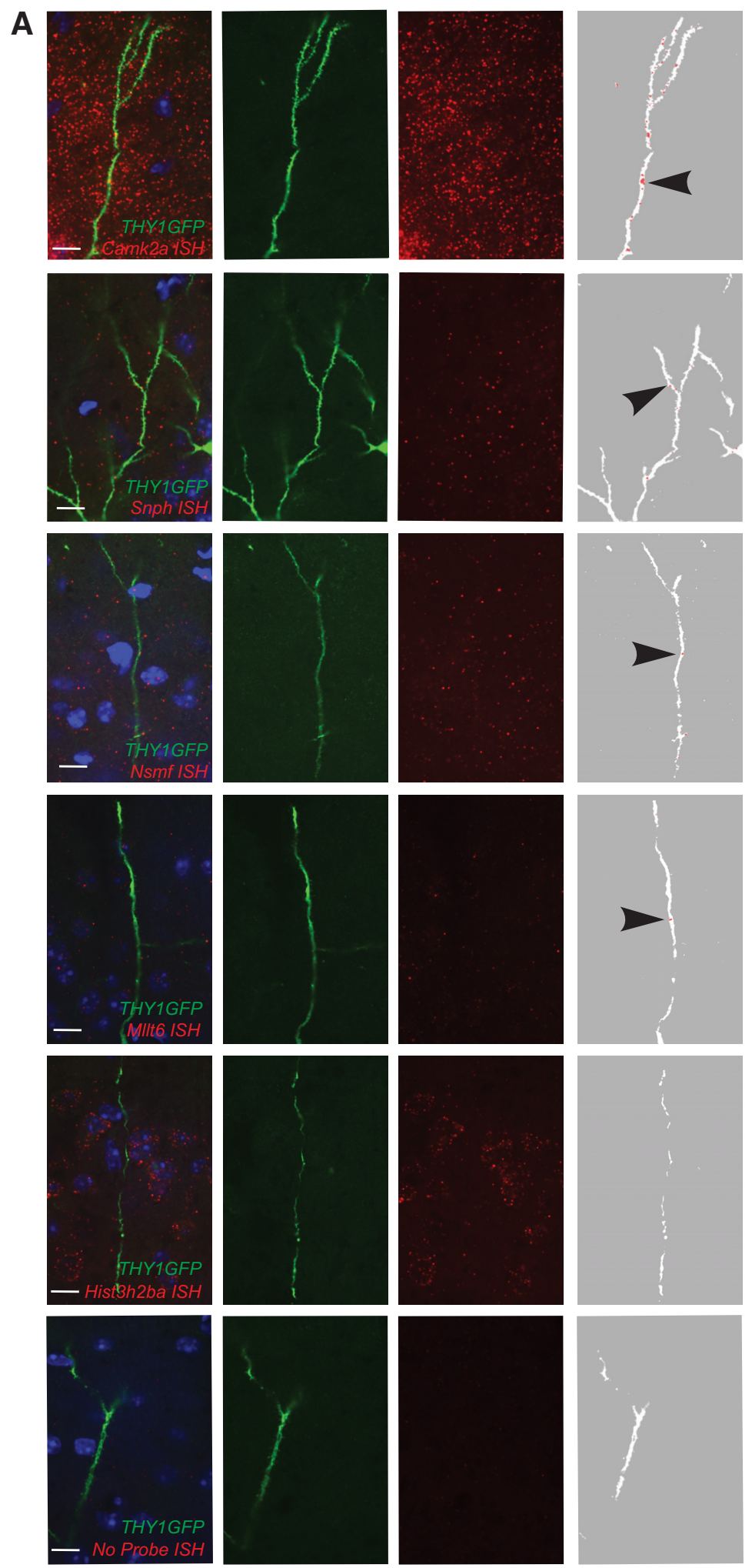

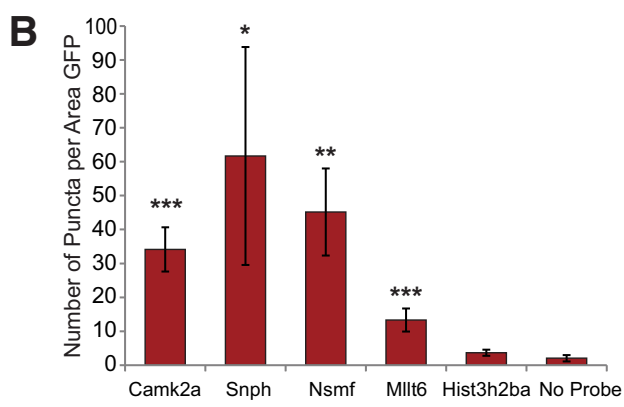

Camk2a Snph Nsmf Mllt6 Hist3h2ba No Probe

Figure 7. Validation by ISH. A, In situ hybridizations of SynapTRAP candidates (red), neuronal process (green), and DAPI (blue) on $20 \mu \mathrm{m}$ brain slices from Tg(Thy1-EGFP)M ${ }^{\mathrm{Jrs} / \mathrm{J}}$ mice. Arrows indicate an example ISH signal overlapping with a neurite. $\boldsymbol{B}$, Quantification of the number of puncta overlapping with GFP labeled processes divided by the area of the image labeled with GFP for each probe. ${ }^{*} p<0.05,{ }^{* *} p<0.01,{ }^{* * *} p<0.001$, unpaired $t$ tests. Error bars \pm SEM. Camk2a: $n=46,76 \mathrm{df}, t=4.06, p=0.0001 ;$ Snph: $n=21,51 \mathrm{df}, t=2.3, p=0.0256 ;$ Nsmf: $n=46,76 \mathrm{df}$, $t=2.79, p=0.0067 ;$ Mllt6: $n=25,55 \mathrm{df}, \mathrm{t}=3.52, p=0.0009 ;$ Hist3hba: $n=19,49 \mathrm{df}, t=1.13, p=0.6231$; No probe: $n=32$.

noted for active shuttling to subcellular compartments (Lawrence and Singer, 1986), and others have shown the presence of these cytoskeletal mRNAs in dendrites and axons (Cajigas et al., 2012; Ainsley et al., 2014; Shigeoka et al., 2016). Thus local trans- lation of additional constituents of these pathways is rational. Yet the robustness of this enrichment overall was unexpected. Cytoskeletal proteins comprised $17.6 \%$ of the candidate list ( $p=$ 4.43E-05) and a 7.7 cluster enrichment score of actin binding 


\section{A GOAnalysis of Local Translation Candidates}

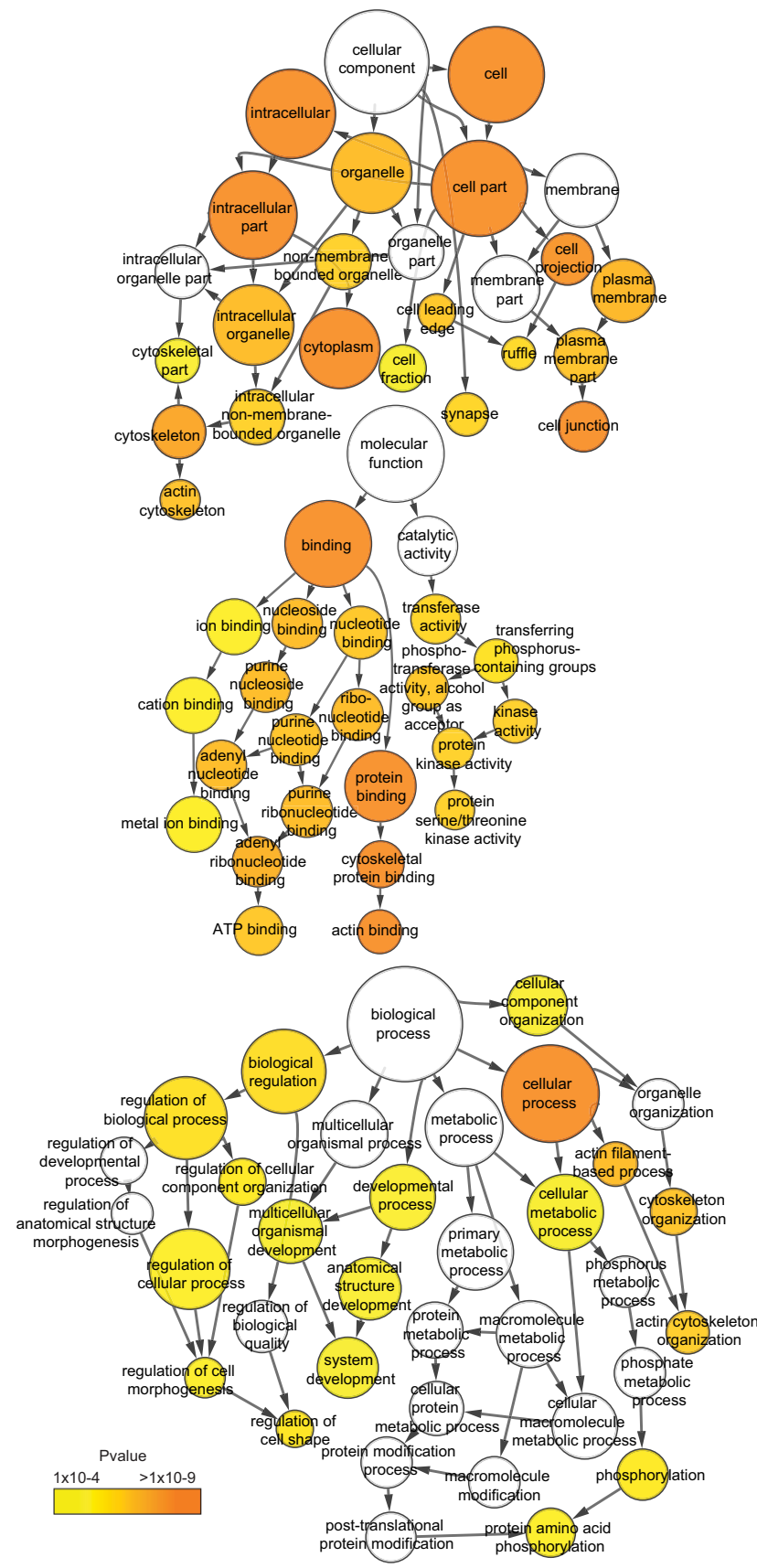

C

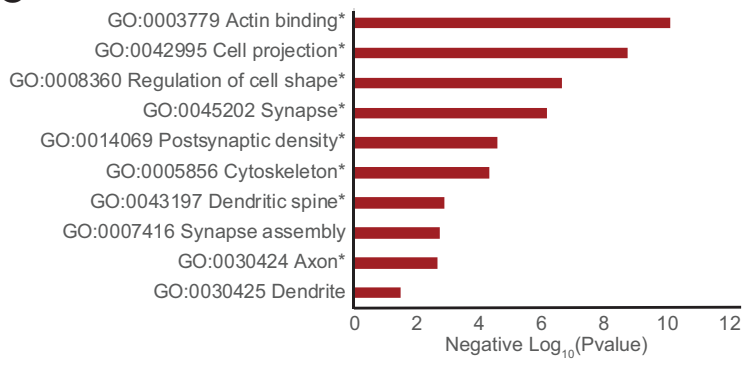

B GOAnalysis of Somatic Translation Candidates

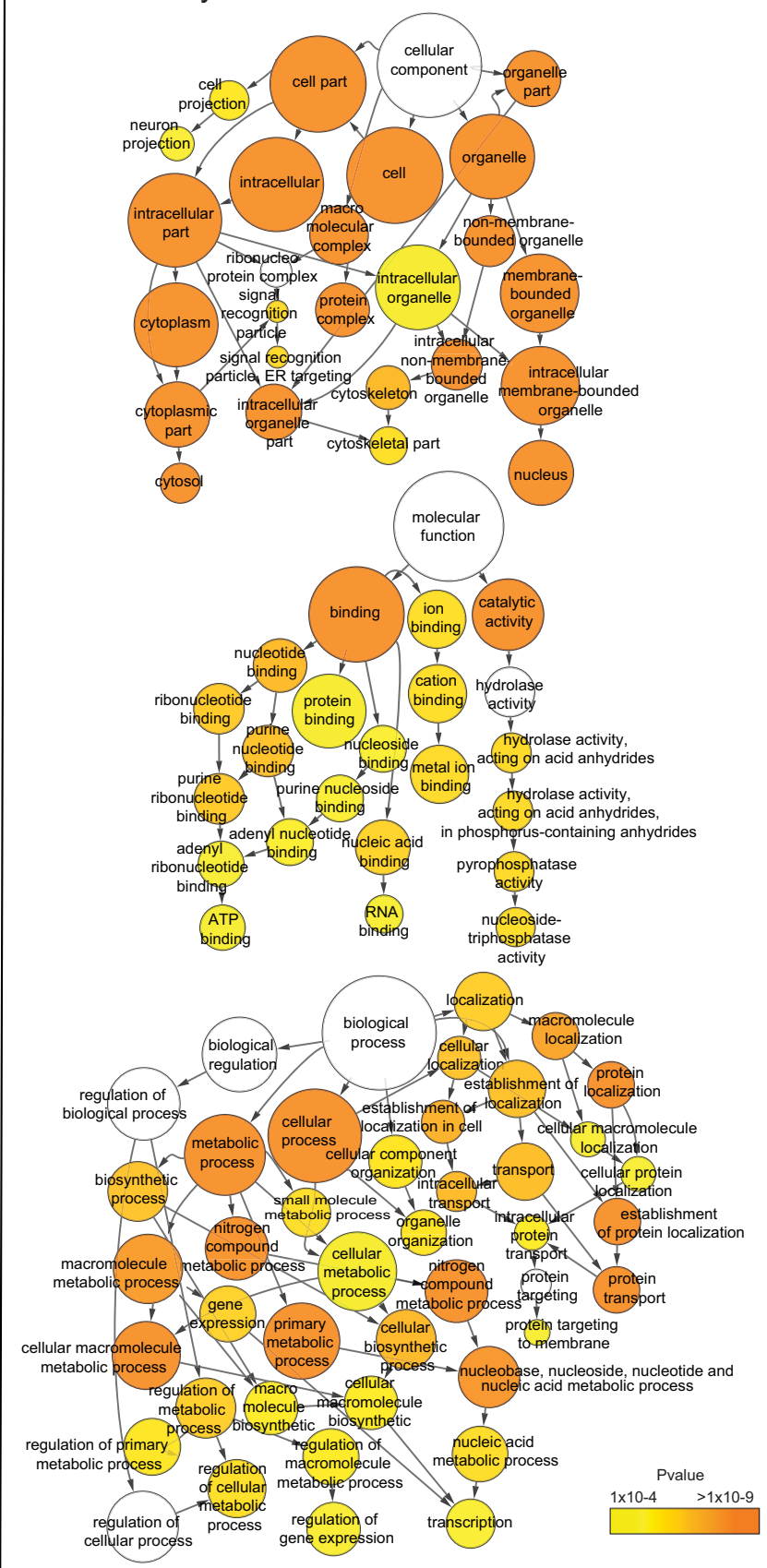

D

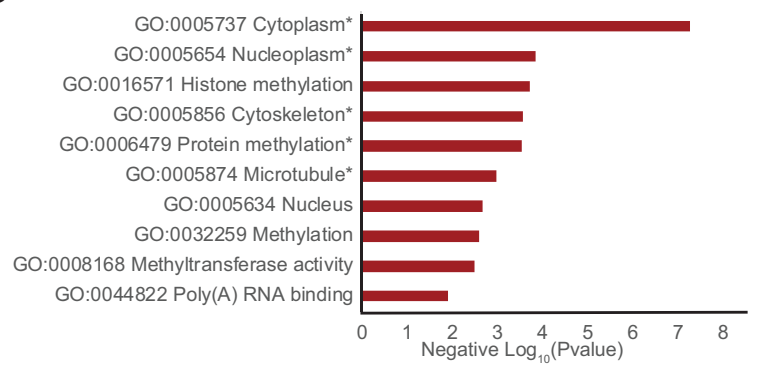

Figure 8. Gene ontologies analysis of candidates lists. Hierarchical network representation of molecular function, cellular component, and biological process $G 0$ analysis for $(\boldsymbol{A})$ local translation candidates and (B) somatic translation candidates with a $p$ value cutoff at $p=0.00001$. Circles are scaled to size of each $G 0$ gene list. Color indicates $p$ value per scale bar. G0 categories are ordered hierarchically from broadest (top) to most specific. C, Ten significant categories from G0 analysis of the local translation candidates (Fig. 8-1 available at https://doi.org/10.1523/JNEUROSCI.3044-16. 2017.f8-1) against the background of genes with transcripts $>2$ CPM in the WCH. D, Ten significant categories from G0 analysis of somatic translation candidates (Fig. 8-2 available at https://doi. org/10.1523/JNEUROSCI.3044-16.2017.f8-2) against the background of genes with transcripts $>2$ CPM in the WCH. *Passes Benjamini-Hochberg correction at FDR $<0.05$. 
proteins from a background of genes represented in the $\mathrm{WCH}$ samples. Overall, these findings emphasize that a primary function of local translation may be structural plasticity of processes. The results are also consistent with the SynapTRAP method accurately measuring classes of transcripts known or hypothesized to be locally translated.

\section{Features of locally translated transcripts}

Next, we sought to determine whether there were sequencespecific mechanisms of localization by analyzing the candidate transcripts for novel motifs, as well as binding by known regulators of local translation. First, we assessed length, GC content, and predicted secondary structure stability across the transcript (Fig. 9A). We found that coding sequence length and GC content are substantially higher in the local translation candidates than in the somatic translation candidates. Furthermore, in the UTR, we found significant differences in length, GC, and structure between local translation candidates and somatic translation candidates in both the $3^{\prime}$ UTR and in the $5^{\prime}$ UTR. Longer sequences, particularly in the $3^{\prime}$ UTR, may permit a greater number of binding motifs for regulating stability, translation, and localization of these transcripts (Andreassi and Riccio, 2009).

One protein known to bind RNA and regulate translation, including local translation, is FMRP. Its targets in the brain have previously been assessed empirically (Darnell et al., 2011). If our method is indeed identifying locally translated mRNAs, then it should enrich for FMRP targets. Indeed, the local translation candidates are significantly enriched in FMRP binding transcripts (Fig. $9 B, C$ ). As both FMRP binding transcripts (Ouwenga and Dougherty, 2015) and local translation candidates are biased toward long transcripts, we confirmed that this finding was not driven by length or expression biases (Fig. 9C).We also analyzed the candidates for enriched motifs between samples. An unbiased screen for motifs using MEME identified a G-rich sequence reminiscent of a G-quartet in the local translation candidates compared with somatic controls. Indeed a full $31 \%$ of candidates had this motif when a direct scan was conducted $\left(\chi^{2}=39.594, \mathrm{df}=1\right.$, $p=3.127 \mathrm{E}-10)$. This is consistent with the increased GC content and secondary structure detected above. The somatic translation candidates on the other hand were found to be enriched for a poly(A) signal by MEME and direct scan $\left(\chi^{2}=4.471, \mathrm{df}=1, p=\right.$ 0.03447 ), though they do not have an increased number of poly(A) signals per transcript (Mann-Whitney test, $U=23841$, $p=0.3414)$. These two motifs were consistently significantly enriched whether MEME was used to directly compare the two lists of local and somatic candidates (discriminative mode), or to determine enrichment based solely on the nucleotide frequencies in the input list (normal mode), which controls for any length bias.

As G-quartets have been previously implicated in FMRP binding (Darnell et al., 2001), we next examined the overlap between all G-quartet-containing transcripts expressed in the brain, FMRP binding mRNAs, and local translation candidates (Fig. $9 F)$. The FMRP set is enriched in G-quartet-containing transcripts (Fisher's exact test, OR 2.2, $p<3.1 \mathrm{E}-11$ ), and $25 \%$ of the overlap between the local translation candidates and FMRP binding might be explained by the presence of a G-quartet (Fisher's exact test, OR $4.2, p<0.0001$ ).

The longer 3' UTRs and presence of consistent motifs also suggests that the local translation candidates might be under greater evolutionary pressure for careful regulation of their protein levels in general. Indeed, examining the set of genes recently shown to be loss-of-function intolerant in human populations
(Lek et al., 2016) reveals that the local translation candidates are enriched in these evolutionarily constrained genes (Fig. 9B). Previously we showed that constrained genes are disproportionately expressed in the brain (Wells et al., 2015); however, brain expression alone does not mediate the enrichment of evolutionarily constrained genes in the local translation candidates, as the neuronally expressed somatic translation candidates show no such enrichment $(p=0.34)$.

\section{Regulation by alternative splicing of isoforms}

An additional mechanism for regulating RNA localization could be alternative splicing of isoforms. A recent study identified alternative splicing of the $3^{\prime}$ UTR as a potential regulatory mechanism for localizing transcripts to the processes of cultured neuroblastoma cells and neurons, and highlighted the surprising result that distal last exons are disproportionately found in processes (Taliaferro et al., 2016). Mixture of isoforms analysis (MISO) calculates the percentage spliced in $(\Psi)$ of each pair of alternatively spliced isoforms in a sample and compares these percentages across samples $(\Delta \Psi)$. MISO identified dozens of neuronal transcripts that may exhibit differential localization based on splicing (Fig. 10A, and Figs. 10-1 and 10-2 available at https://doi.org/10.1523/JNEUROSCI.3044-16.2017.f10-1 and https://doi.org/10.1523/JNEUROSCI.3044-16.2017.f10-2, respectively) at a nominal $p<0.05$. Many of these transcripts encode for proteins with known synaptic functions, such as Gria2 and Ncam1. Another example is Dtna, in which aligned reads are disproportionally include the more distal last exon in the samples from cellular processes (SNF and SynapTRAP; Fig. 10B). Although, in concordance with the in vitro study, the majority $(75 \%)$ of significant neurite-localized alternative last exons (ALE) demonstrated enrichment of the distal last exon, we did not find that this enrichment was significantly biased toward neurites rather than somatic candidates (Fig. $10 C ; \chi^{2}=1.102$, $\mathrm{df}=1, p=0.2938$ ). Although on average, neuronally expressed ALEs showed a slight increase in percentage splicing of the distal last exon in SNF compared with WCH, this difference was not significant (Fig. 10C, left; one-tailed $t$ test, $t=-1.121$, df $=136$, $p=0.264$ ). We did, however, detect a slight preference for distal ALEs to be enriched on ribosomal bound mRNA as seen in the TRAP/WCH comparison (Fig. 10C, middle; one-tailed $t$ test, $t=-2.812, \mathrm{df}=147, p<0.01)$.

\section{Discussion}

In this study we describe SynapTRAP, a method to harvest cell-type-specific mRNA from processes in vivo. We apply it to provide the first description of neurite localized and ribosomebound transcripts in cortex, and identify sequence motifs enriched in these transcripts. Translation at the synapse and in neural processes is important for synaptic formation and plasticity. Understanding the specific mRNAs that are translated near the synapse could uncover novel pathways of synaptic regulation. Whereas fractionation based on density alone yields a SNF that includes RNA from multiple cell types, combining it with SynapTRAP identified locally translated mRNA in cell-specific projections. Analysis of the local translation candidates identified through SynapTRAP of cortical neurons highlighted the importance of cytoskeletal regulation as well as differences in RNA sequence features that localize to neurites. This is consistent with SynapTRAP successfully isolating locally translated mRNAs with shared biological regulation, and indicates that transcripts locally translated in the cortex are enriched for sequences under evolutionary pressure in humans. 
A

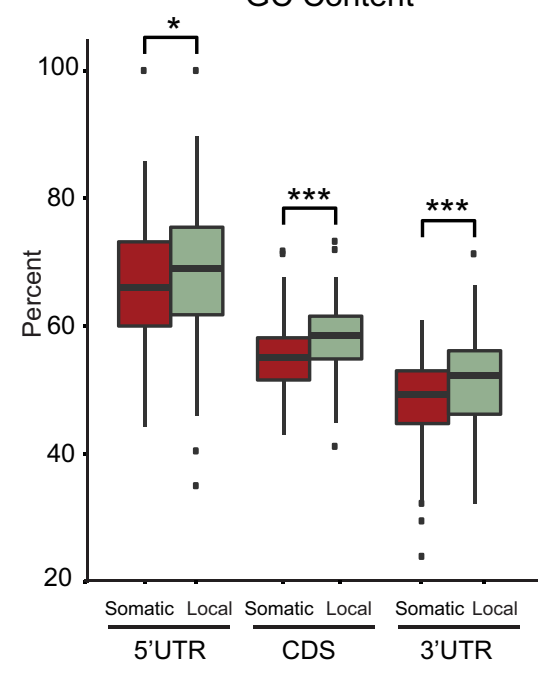

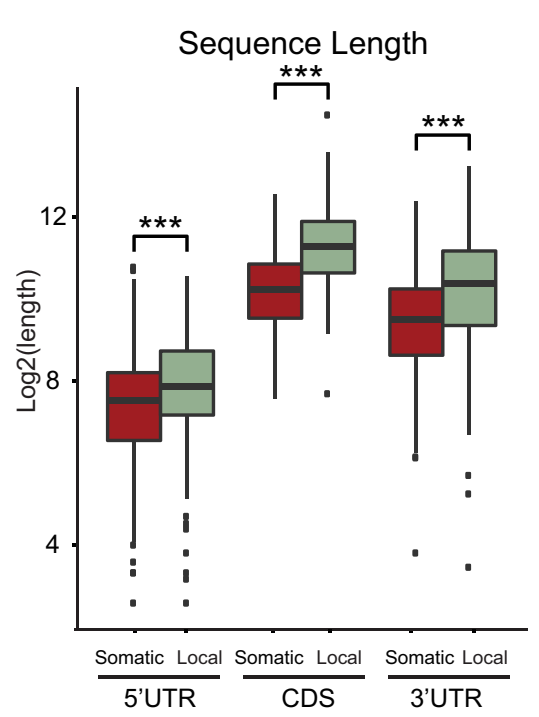

RNA Structure Stability

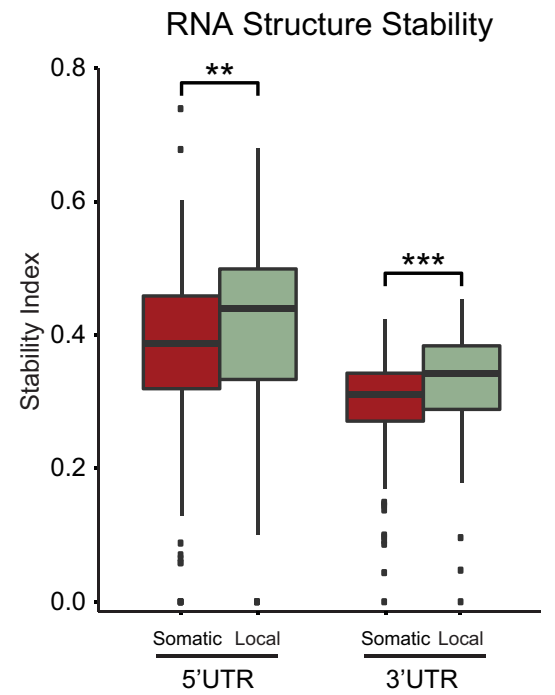

B

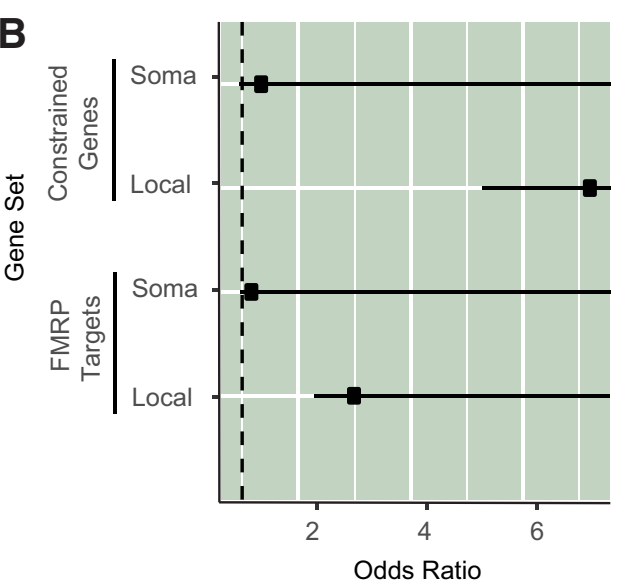

C

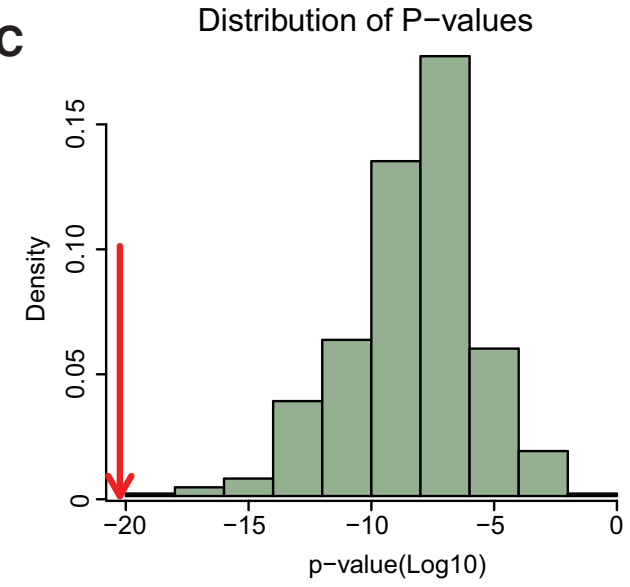

D

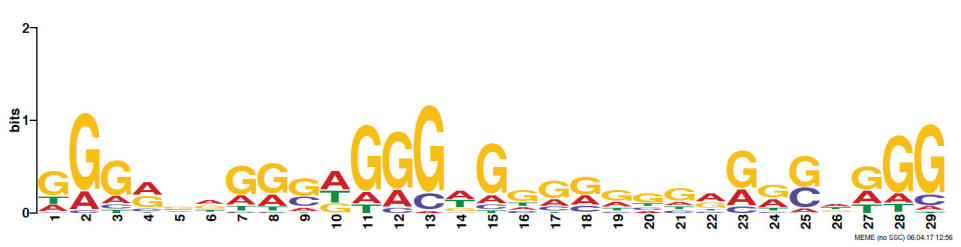

E

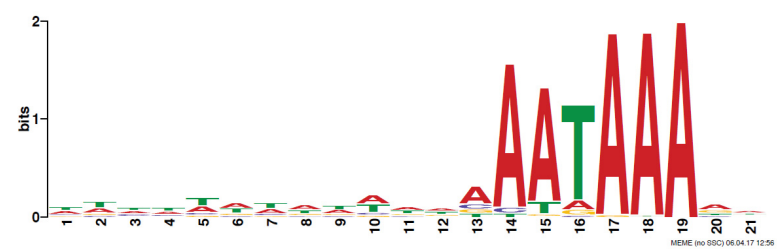

F FMRP Targets

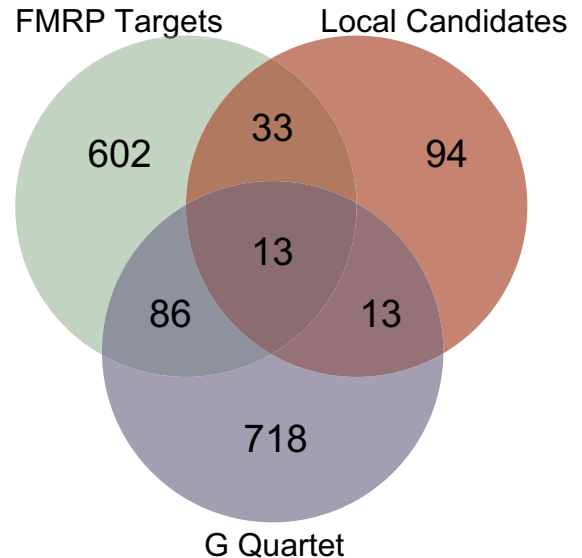

Figure 9. Overrepresented sequence features in local translation candidates. A, Local translation candidates have longer $5^{\prime}$ UTRs, $3^{\prime}$ UTRs, and coding regions (CDS) than somatic controls. Welch's two-tailed $t$ test with Benjamini-Hochberg $(\mathrm{BH})$ correction: $5^{\prime}$ UTR: $t=2.10, \mathrm{df}=250.57, p=0.037 ; \mathrm{CDS}: t=5.35, \mathrm{df}=255.87, p=7.26 \mathrm{E}-07 ; 3^{\prime} \mathrm{UTR}: t=3.74, \mathrm{df}=254.46, p=3.66 \mathrm{E}-04$. Local translation candidates are higher in $5^{\prime}$ UTR, $3^{\prime}$ UTR, and CDS GC content than somatic controls. Welch's two-tailed $t$ test with BH correction: $5^{\prime}$ UTR: $t=3.13$, df $=278.96, p=2.61 \mathrm{E}-03 ;$; CSS: $t=10.51, \mathrm{df}=266.92, p=5.94 \mathrm{E}-21 ; 3^{\prime}$ UTR: $t=5.30, \mathrm{df}=234.98, p=7.26 \mathrm{E}-07$. Local translation candidates have more stable UTR secondary structures than somatic controls. Welch's two-tailed $t$ test with BH correction: $5^{\prime}$ UTR: $t=2.76, \mathrm{df}=266.31 p=6.98 \mathrm{E}-03 ; 3^{\prime} \mathrm{UTR}: t=4.08, \mathrm{df}=250.42, p=1.23 \mathrm{E}-04 .{ }^{* * *} p<0.001,{ }^{* *} p<0.01,{ }^{*} p<0.05, \mathrm{BH}$ corrected. $B$, Local translation candidates are enriched in constrained genes and targets of FMRP; odds ratios and $95 \%$ confidence intervals shown. One-tailed Fisher's exact test, constrained genes: $p<8 \mathrm{E}-8$; FMRP targets: $p<10 \mathrm{E}-16$. C, Distribution of $p$ values after Fisher exact testing of 1000 random gene lists sampled to match the FMRP targets on length and expression biases. $P$ value of true target list indicated with red arrow. D, Top motif discovered in 3' UTRs of local translation candidates ( $E$ value $=8.4 \mathrm{E}-090$, detected in 131/145 sequences). Sequence matches canonical G-quartet motif. $\boldsymbol{E}$, Top motif discovered in 3' UTRs of somatic translation candidates ( $E$ value $=3.9 \mathrm{e}-189$, detected in 310/310 sequences). This matches the canonical poly(A) signal. $\boldsymbol{F}$, Overlap of local translation candidates, G-quartet-containing sequences, and FMRP targets. 
A
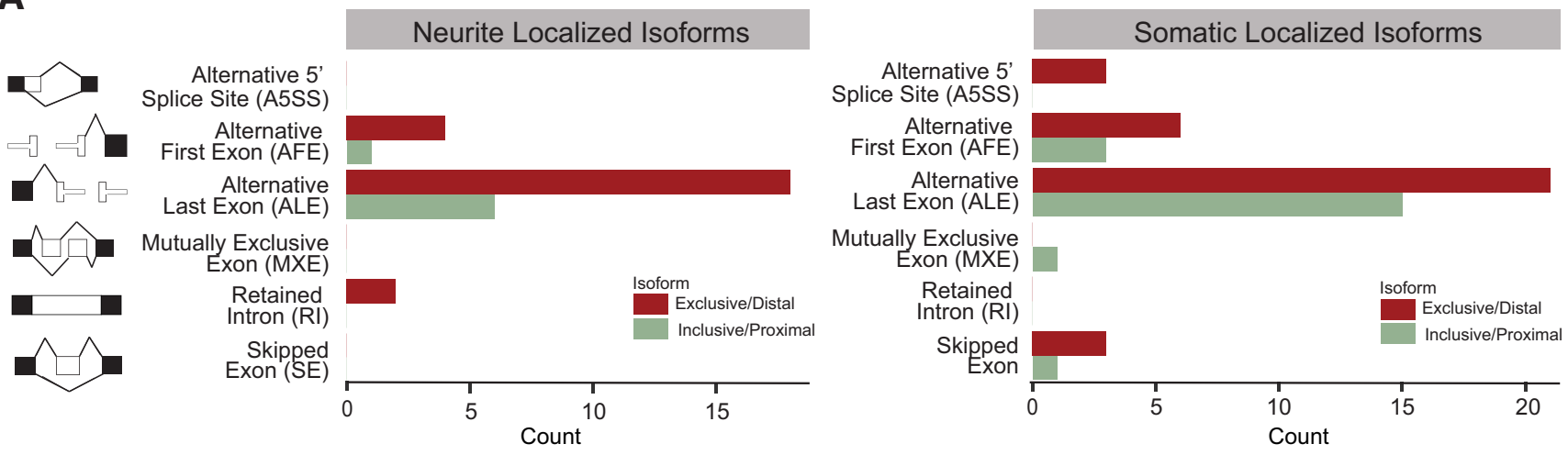

B
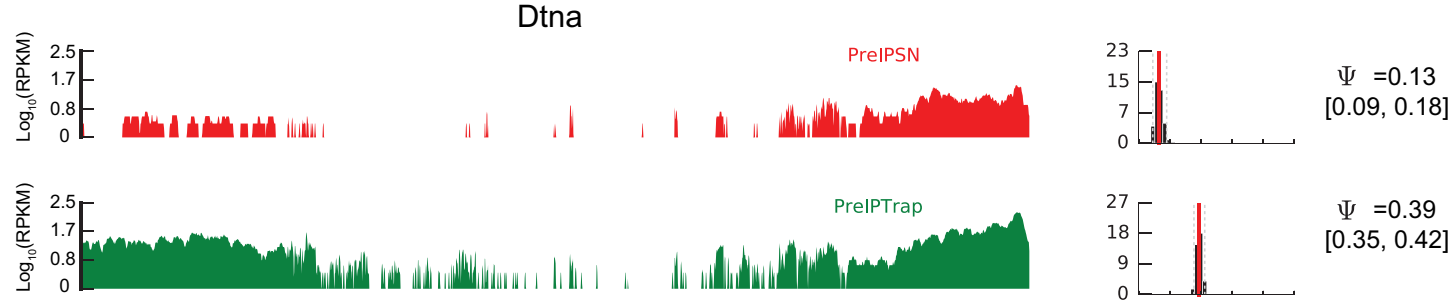

$\Psi=0.39$

$[0.35,0.42]$
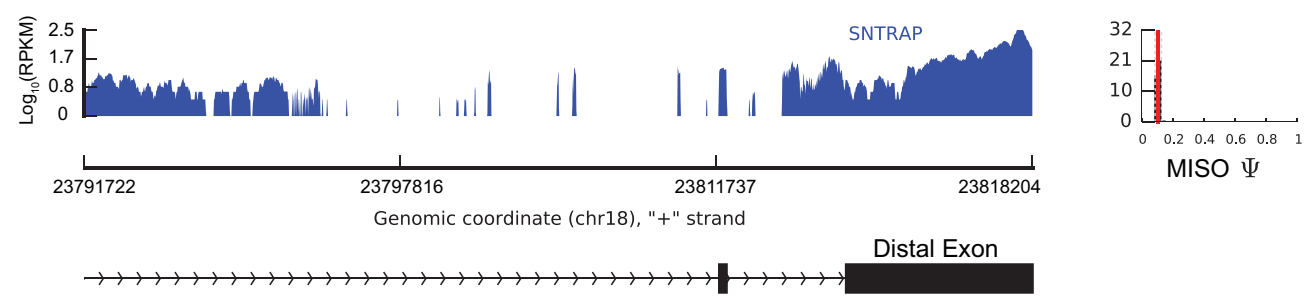

$\Psi=0.10$

$[0.08,0.13]$

\section{Proximal Exon}
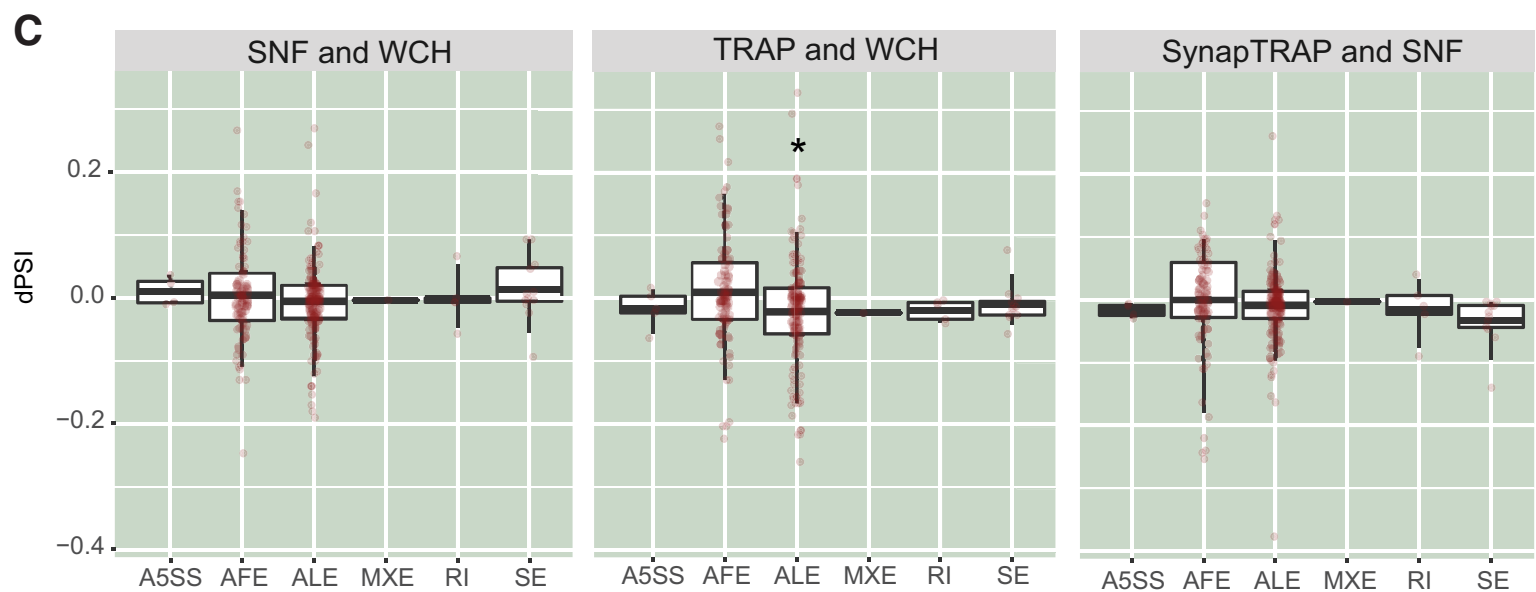

Figure 10. Regulation of transcript localization by alternative splicing. A, Counts of neurite (Fig. 10-1 available at https://doi.org/10.1523/JNEUROSCI.3044-16.2017.f10-1) and somatic (Fig. 10-2 available at https://doi.org/10.1523/JNEUROSCI.3044-16.2017.f10-2) localized splice isoforms for each alternative splicing event type. Events are summarized by whether the localized isoform was the exclusion/distal (red) or inclusion/proximal (green) isoform. B, Distribution of RNA-seq reads across transcript Dtna, an example of a transcript containing a neurite-enriched distal last exon $(p<0.05$, permuted $t$ test). One representative sample from WCH, SNF, and SynapTRAP groups are shown. Right, Percentage spliced in $(\Psi)$ with $95 \%$ confidence intervals for each sample shown. C, Distribution of $\Delta \Psi$ values for pairwise comparisons of the four samples. ${ }^{*} p<0.05$.

Local translation measures for intermixed cell types

Studies of diverse cell types in the brain have already shown cellspecific translational profiles (Doyle et al., 2008), but changes in local translation across cell types have yet to be systematically explored. Though substantial methodological differences pre- clude any quantitative comparison, the local translation candidates detected here from cortical neurites significantly overlap with those discovered in multiple prior studies in hippocampus (Fig. 5E), including those generated by RNA-seq and in situ hybridization (Lein et al., 2007), though it did not overlap with 
others (Poon et al., 2006; Kratz et al., 2014). This lack of consistently (and among these studies themselves) may be due to methodological differences including in vitro versus in vivo, developmental time point, ribosome binding, statistical thresholds and approaches, or differences between local translation of the CNS regions studied.

The ability of SynapTRAP to harvest processes from densely interwoven cell types expands the number of cell types in which local translation can be studied in the CNS, beyond the prior work limited to dendritic lamina. Moreover, as pointed out by Ainsley et al. (2014), cell types that have been studied using dissection methods alone still harvests other cell bodies harvest along with the neurite layers. Immunoblots of the SNF harvested by density fractionation show depletion for nuclei of neurons and glia (NeuN and OLIG2; Fig. 1C), indicating decreased somatic presence in the samples. Coupling SynapTRAP with a variety of TRAP mouse lines (Doyle et al., 2008; Dalal et al., 2013; Dougherty et al., 2013), and availability of Cre-dependent reporters (Sanz et al., 2009; Zhou et al., 2013) should allow for comparative analysis of local translation across a variety of cell types. We are particularly interested in comparative analysis of neurons with markedly different dendritic morphologies. As gene ontology analysis of local translation candidates highlight local transcripts that are involved with regulating cell shape and structure, some of the morphological differences across cell types could be due to differences in regulation of local translation.

\section{Opportunities for further development}

The most significant opportunity for further development of this method would be in reducing the background of the SynapTRAP/SNF comparison to the point that it approaches more typical TRAP/WCH comparisons. We do not think the increased background in SynapTRAP is driven by low levels of eGFPRpl10a expression in glia because, if so, the TRAP/WCH comparisons would show identical levels of background. Rather, there is either something about the physical process of generating the SNF, or the nature of these distal and intermingled processes in the brain that result in an increase in apparent relative levels of mRNA from other cell types being captured. We speculate that the high level of background might be due to nonspecific interactions between RNA granules from neurons and glia post-lysis, as these are formed by very nonspecific interactions between disordered domains in a variety of RNA binding proteins, and can become very stable, even amyloid-like, under certain biophysical conditions (Lin et al., 2015). There were also substantially more reads from mitochondria and mitochondrial rRNA in the SNF/ SynapTRAP fractions. Because of this background, we deliberately focused only on the most enriched transcripts for downstream analyses. These likely represent only a subset of all transcripts that may contribute to translation in neurites. Thus, methodological improvements may further increase the number of candidates detected with this approach. However, the current approach has proven successful at detecting localized RNAs from a previously inaccessible cell type.

Many different biochemical approaches for harvesting cellular processes exist. We selected this density gradient technique because it has been shown to harvest viable synaptic structures that are competent for translation in response to stimulation (Westmark et al., 2011); however, alternative methods might allow for selection for other specialized forms of dendrites or synapses (e.g., glomeruli in the cerebellum; Viennot et al., 1991), or permit analysis of other tissues where filters rather than density centrifugation may be preferred for generating an SNF (e.g., spi- nal cord; Shinomura et al., 1999). Likewise, study of diseases that cause major changes in density of the cellular processes may require optimization of the gradient for consistent collection of the SNF across conditions. Nonetheless, the current protocol should be directly applicable to cell types in cortex and other regions with similar physical properties in the CNS.

Our current method of harvesting GFP-tagged ribosomes in the presence of the elongation inhibitor cycloheximide cannot distinguish if these ribosomes were actively translating. Although ribosome occupancy is a prerequisite for translation, culture studies have shown that transcripts are transported in neurons while bound to ribosomes in a stalled state (Graber et al., 2013). Therefore, it would be of interest in future studies to combine SynapTRAP with stimulation, runoff studies, or indeed even nucleotide resolution analyses of translation to better distinguish to what extent our candidates are stalled and which protein species are being produced.

Finally the presence of substantial glial RNA in the SNF before SynapTRAP (Fig. 2) was also intriguing. This indicated that RNA from some glial processes might be cofractionating with synaptoneurosomes, consistent with prior proteomic studies that identified glial derived proteins in synaptic fractions (Pielot et al., 2012). Indeed, astrocytes have fine processes that interact with synapses providing both trophic and homeostatic support, and microglial processes show great motility in the CNS, apparently surveying and phagocytosing nearby synapses (Perea et al., 2009; Schafer et al., 2013). Using a variation of the SynapTRAP approach we have also now just shown that astrocytes also have potential for local translation as well (Sakers et al., 2017).

\section{Identification of mechanisms of regulating local translation}

Downstream analysis of candidates identified by SynapTRAP can be analyzed in many ways using bioinformatics. For example, the increased UTR length and secondary structure of local translation candidates is consistent with the region's regulatory role. It will also be of great interest in future investigations to determine whether transcript localization shows UTR-regulated differences between cell types, and whether the evolutionary constraint on the protein coding sequence for several local translation candidates also extends to motifs in their 3' UTRs.

Our studies are also consistent with prior models indicating that FMRP plays a role in regulating local translation in the cortex, and that this might be mediated by interactions with G-quartet motifs. In addition, differential splicing also likely regulates isoform enrichment on neurite ribosomes for a set of transcripts, consistent with a recent study of axonal RNA (Shigeoka et al., 2016) and cultured neurites (Taliaferro et al., 2016), though whether the distal ALEs are disproportionately enriched compared with somatic ribosomes is unclear from our data. This is in contrast with prior work indicating a clear preference for distal last exons in process localized transcripts (Taliaferro et al., 2016). However, this contrast could reflect differences between in vivo and in vitro systems, relative phase of maturation of the processes (neurite outgrowth in vitro compared with an age more associated with synaptic refinement in vivo), or differences in cell types. Regardless, these findings suggest that different mechanisms are used to regulate localization in different contexts, and both analyses support the importance of 3' UTRs.

In addition to the G-quartet, we identified other $3^{\prime}$ UTR motifs that may contribute to regulation of local translation. Specifically, we identified an increased number of strong polyadenylation signals in Somatic Translation Candidates. This suggests regulation of poly(A) tail length might contribute to RNA local- 
ization or ribosome binding, and will be an interesting area for future exploration. Though further evidence for these specific models awaits additional computational and functional studies, overall the presence of significant motifs in the 3' UTRs supports the hypothesis that these regions of the transcript are particularly important for regulation of location and translation.

\section{Applications to disease}

As ASD-related syndromes such as fragile X syndrome and tuberous sclerosis have been previously hypothesized as a diseases of altered translation at the synapse (Kelleher and Bear, 2008), it is notable that the list of local translation candidates significantly overlaps with FMRP targets. The overlap of these two list is significant even after correction for length and expression bias of transcripts (Ouwenga and Dougherty, 2015), and a binding sequence for FMRP is enriched in the local translation candidates. This is consistent with the hypothesized role for FMRP in regulation of locally translated transcripts during transport to neuronal processes (Darnell et al., 2011). This also suggests SynapTRAP could be a viable way to identify perturbations in local translation across specific neuronal populations and in disease models in the future.

\section{References}

Ainsley JA, Drane L, Jacobs J, Kittelberger KA, Reijmers LG (2014) Functionally diverse dendritic mRNAs rapidly associate with ribosomes following a novel experience. Nat Commun 5:4510. CrossRef Medline

Anders S, Pyl PT, Huber W (2015) HTSeq: a python framework to work with high-throughput sequencing data. Bioinformatics 31:166-169. CrossRef Medline

Andreassi C, Riccio A (2009) To localize or not to localize: mRNA fate is in 3'UTR ends. Trends Cell Biol 19:465-474. CrossRef Medline

Bailey TL, Elkan C (1994) Fitting a mixture model by expectation maximization to discover motifs in biopolymers. Proc Int Conf Intell Syst Mol Biol 2:28-36. Medline

Bolger AM, Lohse M, Usadel B (2014) Trimmomatic: a flexible trimmer for Illumina sequence data. Bioinformatics 30:2114-2120. CrossRef Medline

Bright NJ, Carling D, Thornton C (2008) Investigating the regulation of brain-specific kinases 1 and 2 by phosphorylation. J Biol Chem 283: 14946-14954. CrossRef Medline

Burgin KE, Waxham MN, Rickling S, Westgate SA, Mobley WC, Kelly PT (1990) In situ hybridization histochemistry of $\mathrm{Ca}^{2+} /$ calmodulindependent protein kinase in developing rat brain. J Neurosci 10:17881798. Medline

Cajigas IJ, Tushev G, Will TJ, tom Dieck S, Fuerst N, Schuman EM (2012) The local transcriptome in the synaptic neuropil revealed by deep sequencing and high-resolution imaging. Neuron 74:453-466. CrossRef Medline

Dalal J, Roh JH, Maloney SE, Akuffo A, Shah S, Yuan H, Wamsley B, Jones WB, de Guzman Strong C, Gray PA, Holtzman DM, Heintz N, Dougherty JD (2013) Translational profiling of hypocretin neurons identifies candidate molecules for sleep regulation. Genes Dev 27:565-578. CrossRef Medline

Dani A, Huang B, Bergan J, Dulac C, Zhuang X (2010) Superresolution imaging of chemical synapses in the brain. Neuron 68:843-856. CrossRef Medline

Darnell JC, Jensen KB, Jin P, Brown V, Warren ST, Darnell RB (2001) Fragile $\mathrm{X}$ mental retardation protein targets $\mathrm{G}$ quartet mRNAs important for neuronal function. Cell 107:489-499. CrossRef Medline

Darnell JC, Van Driesche SJ, Zhang C, Hung KY, Mele A, Fraser CE, Stone EF, Chen C, Fak JJ, Chi SW, Licatalosi DD, Richter JD, Darnell RB (2011) FMRP stalls ribosomal translocation on mRNAs linked to synaptic function and autism. Cell 146:247-261. CrossRef Medline

Dobin A, Davis CA, Schlesinger F, Drenkow J, Zaleski C, Jha S, Batut P, Chaisson M, Gingeras TR (2013) STAR: ultrafast universal RNA-seq aligner. Bioinformatics 29:15-21. CrossRef Medline

Dougherty JD, Schmidt EF, Nakajima M, Heintz N (2010) Analytical approaches to RNA profiling data for the identification of genes enriched in specific cells. Nucleic Acids Res 38:4218-4230. CrossRef Medline
Dougherty JD, Fomchenko EI, Akuffo AA, Schmidt E, Helmy KY, Bazzoli E, Brennan CW, Holland EC, Milosevic A (2012) Candidate pathways for promoting differentiation or quiescence of oligodendrocyte progenitorlike cells in glioma. Cancer Res 72:4856-4868. CrossRef Medline

Dougherty JD, Maloney SE, Wozniak DF, Rieger MA, Sonnenblick L, Coppola G, Mahieu NG, Zhang J, Cai J, Patti GJ, Abrahams BS, Geschwind DH, Heintz N (2013) The disruption of Celf6, a gene identified by translational profiling of serotonergic neurons, results in autism-related behaviors. J Neurosci 33:2732-2753. CrossRef Medline

Doyle JP, Dougherty JD, Heiman M, Schmidt EF, Stevens TR, Ma G, Bupp S, Shrestha P, Shah RD, Doughty ML, Gong S, Greengard P, Heintz N (2008) Application of a translational profiling approach for the comparative analysis of CNS cell types. Cell 135:749-762. CrossRef Medline

Epstein I, Tushev G, Will TJ, Vlatkovic I, Cajigas IJ, Schuman EM (2014) Alternative polyadenylation and differential expression of shank mRNAs in the synaptic neuropil. Philos Trans R Soc Lond B Biol Sci 369:20130137. Medline

Graber TE, Hébert-Seropian S, Khoutorsky A, David A, Yewdell JW, Lacaille JC, Sossin WS (2013) Reactivation of stalled polyribosomes in synaptic plasticity. Proc Natl Acad Sci U S A 110:16205-16210. CrossRef Medline

Heiman M, Schaefer A, Gong S, Peterson JD, Day M, Ramsey KE, SuárezFariñas M, Schwarz C, Stephan DA, Surmeier DJ, Greengard P, Heintz N (2008) A translational profiling approach for the molecular characterization of CNS cell types. Cell 135:738-748. CrossRef Medline

Huang da W, Sherman BT, Lempicki RA (2009) Systematic and integrative analysis of large gene lists using DAVID bioinformatics resources. Nat Protocols 4:44-57. CrossRef Medline

Inoue E, Mochida S, Takagi H, Higa S, Deguchi-Tawarada M, Takao-Rikitsu E, Inoue M, Yao I, Takeuchi K, Kitajima I, Setou M, Ohtsuka T, Takai Y (2006) SAD: a presynaptic kinase associated with synaptic vesicles and the active zone cytomatrix that regulates neurotransmitter release. Neuron 50:261-275. CrossRef Medline

Kang H, Schuman EM (1996) A requirement for local protein synthesis in neurotrophin-induced hippocampal synaptic plasticity. Science 273: 1402-1406. CrossRef Medline

Katz Y, Wang ET, Airoldi EM, Burge CB (2010) Analysis and design of RNA sequencing experiments for identifying isoform regulation. Nat Methods 7:1009-1015. CrossRef Medline

Kelleher RJ 3rd, Bear MF (2008) The autistic neuron: troubled translation? Cell 135:401-406. CrossRef Medline

Kratz A, Beguin P, Kaneko M, Chimura T, Suzuki AM, Matsunaga A, Kato S, Bertin N, Lassmann T, Vigot R, Carninci P, Plessy C, Launey T (2014) Digital expression profiling of the compartmentalized translatome of Purkinje neurons. Genome Res 24:1396-1410. CrossRef Medline

Langmead B, Salzberg SL (2012) Fast gapped-read alignment with Bowtie 2. Nat Methods 9:357-359. CrossRef Medline

Lawrence JB, Singer RH (1986) Intracellular localization of messenger RNAs for cytoskeletal proteins. Cell 45:407-415. CrossRef Medline

Lein ES1, Hawrylycz MJ, Ao N, Ayres M, Bensinger A, Bernard A, Boe AF, Boguski MS, Brockway KS, Byrnes EJ, Chen L, Chen L, Chen TM, Chin MC, Chong J, Crook BE, Czaplinska A, Dang CN, Datta S, Dee NR, et al. (2007) Genome-wide atlas of gene expression in the adult mouse brain. Nature 445:168-176. CrossRef Medline

Lek M, Karczewski KJ, Minikel EV, Samocha KE, Banks E, Fennell T, O'Donnell-Luria AH, Ware JS, Hill AJ, Cummings BB, Tukiainen T, Birnbaum DP, Kosmicki JA, Duncan LE, Estrada K, Zhao F, Zou J, PierceHoffman E, Berghout J, Cooper DN, et al. (2016) Analysis of proteincoding genetic variation in 60,706 humans. Nature 536:285-291. CrossRef Medline

Lin Y, Protter DS, Rosen MK, Parker R (2015) Formation and maturation of phase-separated liquid droplets by RNA-binding proteins. Molecular Cell 60:208-219. CrossRef Medline

Lorenz R, Bernhart SH, Höner Zu Siederdissen C, Tafer H, Flamm C, Stadler PF, Hofacker IL (2011) ViennaRNA package 2.0. AMB 6:26. CrossRef Medline

Lu R, Niida H, Nakanishi M (2004) Human SAD1 kinase is involved in UV-induced DNA damage checkpoint function. J Biol Chem 279:3116431170. CrossRef Medline

Maere S, Heymans K, Kuiper M (2005) BiNGO: a cytoscape plugin to assess overrepresentation of gene ontology categories in biological networks. Bioinformatics 21:3448-3449. CrossRef Medline

McCarthy DJ, Chen Y, Smyth GK (2012) Differential expression analysis of 
multifactor RNA-seq experiments with respect to biological variation. Nucleic Acids Res 40:4288-4297. CrossRef Medline

Meyer-Luehmann M, Mielke M, Spires-Jones TL, Stoothoff W, Jones P, Bacskai BJ, Hyman BT (2009) A reporter of local dendritic translocation shows plaque-related loss of neural system function in APP-transgenic mice. J Neurosci 29:12636-12640. CrossRef Medline

Müller M, Lutter D, Püschel AW (2010) Persistence of the cell-cycle checkpoint kinase Wee1 in SadA- and SadB-deficient neurons disrupts neuronal polarity. J Cell Science 123:286-294. CrossRef Medline

Ouwenga RL, Dougherty J (2015) Fmrp targets or not: long, highly brainexpressed genes tend to be implicated in autism and brain disorders. Mol Autism 6:16. CrossRef Medline

Perea G, Navarrete M, Araque A (2009) Tripartite synapses: astrocytes process and control synaptic information. Trends Neurosci 32:421-431. CrossRef Medline

Pielot R, Smalla KH, Müller A, Landgraf P, Lehmann AC, Eisenschmidt E, Haus UU, Weismantel R, Gundelfinger ED, Dieterich DC (2012) SynProt: a database for proteins of detergent-resistant synaptic protein preparations. Front Synaptic Neurosci 4:1. CrossRef Medline

Poon MM, Choi SH, Jamieson CA, Geschwind DH, Martin KC (2006) Identification of process-localized mRNAs from cultured rodent hippocampal neurons. J Neurosci 26:13390-13399. CrossRef Medline

Qin M, Kang J, Burlin TV, Jiang C, Smith CB (2005) Postadolescent changes in regional cerebral protein synthesis: an in vivo study in the Fmr1 null mouse. J Neurosci 25:5087-5095. CrossRef Medline

Reddy AS, O'Brien D, Pisat N, Weichselbaum CT, Sakers K, Lisci M, Dalal JS, Dougherty JD (2017) A comprehensive analysis of cell type-specific nuclear RNA from neurons and glia of the brain. Biol Psychiatry 81:252-264. CrossRef Medline

Ronesi JA, Huber KM (2008) Metabotropic glutamate receptors and fragile $\mathrm{X}$ mental retardation protein: partners in translational regulation at the synapse. Sci Signal 1:pe6. CrossRef Medline

Sakers K, Lake AM, Khazanchi R, Ouwenga R, Vasek MJ, Dani A, Dougherty JD (2017) Astrocytes locally translate transcripts in their peripheral processes. Proc Natl Acad Sci U S A 114:E3830-E3838. CrossRef Medline

Sanz E, Yang L, Su T, Morris DR, McKnight GS, Amieux PS (2009) Celltype-specific isolation of ribosome-associated mRNA from complex tissues. Proc Natl Acad Sci U S A 106:13939-13944. CrossRef Medline

Schafer DP, Lehrman EK, Stevens B (2013) The "quad-partite" synapse: microglia-synapse interactions in the developing and mature CNS. Glia 61:24-36. CrossRef Medline

Shigeoka T, Jung H, Jung J, Turner-Bridger B, Ohk J, Lin JQ, Amieux PS, Holt CE (2016) Dynamic axonal translation in developing and mature visual circuits. Cell 166:181-192. CrossRef Medline

Shinomura T, Nakao S, Adachi T, Shingu K (1999) Clonidine inhibits and phorbol acetate activates glutamate release from rat spinal synaptoneurosomes. Anesth Analg 88:1401-1405. CrossRef Medline

Steward O, Levy WB (1982) Preferential localization of polyribosomes under the base of dendritic spines in granule cells of the dentate gyrus. J Neurosci 2:284-291. Medline
Steward O, Farris S, Pirbhoy PS, Darnell J, Driesche SJ (2014) Localization and local translation of Arc/Arg3.1 mRNA at Synapses: some observations and paradoxes. Front Mol Neurosci 7:101. CrossRef Medline

Suleiman H, Zhang L, Roth R, Heuser JE, Miner JH, Shaw AS, Dani A (2013) Nanoscale protein architecture of the kidney glomerular basement membrane. eLife 2:e01149. CrossRef Medline

Taliaferro JM, Vidaki M, Oliveira R, Olson S, Zhan L, Saxena T, Wang ET, Graveley BR, Gertler FB, Swanson MS, Burge CB (2016) Distal alternative last exons localize mRNAs to neural projections. Mol Cell 61:821833. CrossRef Medline

Viennot F, Artault JC, Tholey G, De Barry J, Gombos G (1991) An improved method for the preparation of rat cerebellar glomeruli. J Neurosci Methods 38:51-62. CrossRef Medline

Wang ET, Sandberg R, Luo S, Khrebtukova I, Zhang L, Mayr C, Kingsmore SF, Schroth GP, Burge CB (2008) Alternative isoform regulation in human tissue transcriptomes. Nature 456:470-476. CrossRef Medline

Wang X, Spandidos A, Wang H, Seed B (2012) PrimerBank: a PCR primer database for quantitative gene expression analysis, 2012 update. Nucleic Acids Res 40:D1144-49. CrossRef Medline

Wells A, Kopp N, Xu X, O’Brien DR, Yang W, Nehorai A, Adair-Kirk TL, Kopan R, Dougherty JD (2015) The anatomical distribution of genetic associations. Nucleic Acids Res 43:10804-10820. CrossRef Medline

Westmark PR, Westmark CJ, Jeevananthan A, Malter JS. (2011) Preparation of synaptoneurosomes from mouse cortex using a discontinuous Percoll-sucrose density gradient. J Vis Exp 55:e3196. CrossRef Medline

Xu X, Wells AB, O’Brien DR, Nehorai A, Dougherty JD (2014) Cell typespecific expression analysis to identify putative cellular mechanisms for neurogenetic disorders. J Neurosci 34:1420-1431. CrossRef Medline

Yoshida H, Goedert M (2012) Phosphorylation of microtubule-associated protein tau by AMPK-related kinases. J Neurochem 120:165-176. CrossRef Medline

Zeisel A, Muñoz-Manchado AB, Codeluppi S, Lönnerberg P, La Manno G, Juréus A, Marques S, Munguba H, He L, Betsholtz C, Rolny C, CasteloBranco G, Hjerling-Leffler J, Linnarsson S (2015) Cell types in the mouse cortex and hippocampus revealed by single-cell RNA-seq. Science 347:1138-1142. CrossRef Medline

Zhang Y, Chen K, Sloan SA, Bennett ML, Scholze AR, O'Keeffe S, Phatnani HP, Guarnieri P, Caneda C, Ruderisch N, Deng S, Liddelow SA, Zhang C, Daneman R, Maniatis T, Barres BA, Wu JQ (2014) An RNA-sequencing transcriptome and splicing database of glia, neurons, and vascular cells of the cerebral cortex. J Neurosci 34:11929-11947. CrossRef Medline

Zhong J, Zhang T, Bloch LM (2006) Dendritic mRNAs encode diversified functionalities in hippocampal pyramidal neurons. BMC Neuroscience 7:17. CrossRef Medline

Zhou P, Zhang Y, Ma Q, Gu F, Day DS, He A, Zhou B, Li J, Stevens SM, Romo $\mathrm{D}, \mathrm{Pu}$ WT (2013) Interrogating translational efficiency and lineagespecific transcriptomes using ribosome affinity purification. Proc Natl Acad Sci U S A 110:15395-15400. CrossRef Medline 